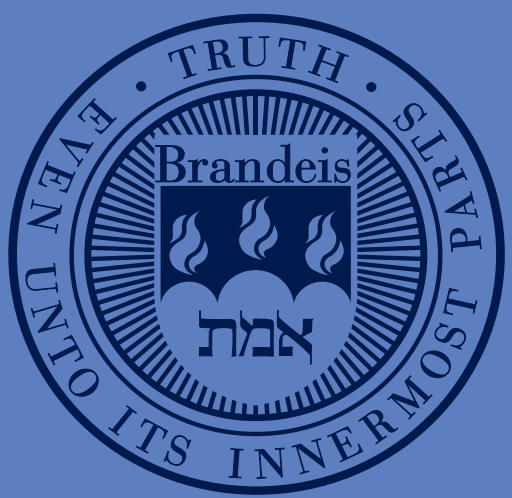

Bank stability and market discipline: The effect of contingent capital on risk taking and default probability

Jens Hilscher, Brandeis International Business School

Alon Raviv, Brandeis International Business School

Working Paper Series 


\section{Bank stability and market discipline: The effect of contingent capital on risk taking and default probability}

\author{
Jens Hilscher* \\ hilscher@brandeis.edu
}

\author{
Alon Raviv ${ }^{\dagger}$ \\ araviv@brandeis.edu
}

This version: September 2012

\footnotetext{
*International Business School, Brandeis University, 415 South Street, Waltham MA 02453, USA. Phone: +1-781-736-2261.

$\dagger$ Corresponding author, International Business School, Brandeis University, 415 South Street, Waltham MA 02453, USA. Phone: +1-781-736-2249.

We would like to thank Jose Berrospide, Steve Cecchetti, Darrell Duffie, Dan Galai, Dwight Jaffee, Robert Jarrow, Yoram Landskroner, Carol Osler, Monica Singhal, Andrea Sironi, Jeremy Stein, Shridhar Sundaram, Zvi Wiener, and seminar participants at Hebrew University of Jerusalem, the FMA meetings (New Orleans, 2004), the EFMA meetings (Milan, 2005), Brandeis University, the Venice C.R.E.D.I.T. conference (2011), the Eastern Finance association meetings (Boston, 2012), and the European Finance Association meetings (Copenhagen, 2012) for their helpful comments and discussion, and Michael Bertini for research assistance. A previous version of this paper was circulated under the title "Bank Stability and Market Discipline: Debt-for-Equity Swap Versus Subordinated Notes."
} 


\begin{abstract}
This paper investigates the effects of financial institutions issuing contingent capital, a debt security that automatically converts into equity if assets fall below a predetermined threshold. We analyze a tractable form of contingent convertible bonds ("coco") and provide a closed-form solution for the price. We quantify the reduction in default probability associated with contingent capital as compared to subordinated debt. We then show that appropriate choice of contingent capital parameters (conversion ratio and threshold) can virtually eliminate stockholders' incentives to risk-shift, a motivation that is present when bank liabilities instead include either only equity or subordinated debt. Importantly, risk-taking incentives continue to be weak during times of financial distress. Our findings imply that contingent capital may be an effective tool for stabilizing financial institutions.
\end{abstract}

JEL Classification: G13, G21, G28, E58

Keywords: contingent capital, executive compensation, risk taking, banking regulation, bank default probability, financial crisis 


\section{Introduction}

Bank capital, primarily in the form of common equity, provides banks with a buffer to absorb losses and protect creditors. In the recent financial crisis there has been a shortfall in the amount and quality of capital held by banks. Financial institutions were not able to raise significant new capital in the market and had to rely instead on governments to provide capital. The extensive amount of implicit guarantees and outright infusion of taxpayer money into large financial institutions has come under much scrutiny.

One of the most prominent suggested solutions for the shortfall of capital in bad times is the introduction of contingent convertible bonds (often simply referred to as "contingent capital" or "coco") into the capital structure of financial institutions. Contingent capital is subordinated debt that automatically converts into equity when a certain stress-related trigger is breached and thus can absorb losses on a going concern basis. Such an automatic debt-to-equity swap or "bail-in" is potentially valuable since it is executed in times of distress.

The market for contingent convertible bonds has already started developing. In November 2009 Lloyds Bank issued contingent convertible bonds that convert into ordinary shares if the consolidated core tier one ratio of Lloyds falls below 5\%. In March 2010, Rabobank issued contingent capital where there is a debt write-down when its regulatory capital ratio falls below 7\%. ${ }^{1}$ Regulators and policymakers have also advocated using contingent capital as a preferred tool for implementing prudential banking regulations. Swiss regulators have required additional capital for the country's systemically important institutions (Credit Suisse and UBS), stating that it can be issued in the form of contingent capital. In the U.S., recent legislation calls for the issuance of contingent capital to be an additional standard potentially faced by systemically important institutions. The Basel Committee and other regulators are also considering the role of contingent capital instruments in regulatory capital requirements.

In this paper we analyze a tractable form of contingent capital that is motivated by the structure of existing securities: The contingent convertible bond has a fixed payoff unless at

\footnotetext{
${ }^{1}$ In both cases the design of the contingent capital securities is similar to the structure which we analyze. In particular, both Lloyds and Rabobank use conversion triggers based on asset value.
} 
any time before maturity the value of assets falls below a pre-specified conversion threshold. ${ }^{2}$ In such an event the debt contract is converted automatically into common equity according to a pre-determined conversion ratio. We present a closed-form solution for the contingent capital price and then use our model to analyze the effect of contingent capital design on the stability of financial institutions.

We begin by introducing contingent convertible bonds into a simple capital structure that also includes deposits and equity. In our setting conversion occurs once asset value touches a pre-determined threshold, while default occurs (the bank is seized) as soon as asset value drops below a threshold related to the amount of deposits outstanding. We thus are using a setting in which both investors (equity and contingent capital holders) as well as regulators (e.g. the FDIC) are continuously monitoring developments at the financial institution. In this setting valuation of the different liabilities is based on standard option pricing as developed by Black, Scholes, and Merton (1973, 1974), and Black and Cox (1976). In an extension we also consider the case of a discrete audit frequency, where investors and regulators observe bank capital only periodically. ${ }^{3}$

Bank instability, in particular during times of financial distress, is a concern that has been at the forefront of the debate regarding the introduction of contingent capital. Using our analytical framework, we consider the stabilizing effect that contingent capital may have. To provide a level playing field we compare a bank issuing contingent capital to one instead issuing subordinated debt, which does not convert into equity in times of distress.

We show that both the inclusion of contingent capital as well as its design can have impor-

\footnotetext{
${ }^{2}$ In addition to being consistent with current market practice, our assumption of conversion resulting from a drop in asset value below a threshold removes the possibility of multiple equilibria that may result from a conversion trigger based on the bank's equity price (e.g. Flannery, 2002). In such a setting conversion may not occur even if the corporation is in a bad standing and vice versa (see Duffie, 2009; Pennacchi, Vermaelen, and Wolff, 2010; Sundaresan and Wang, 2011). Bond, Goldstein, and Prescott (2010) provide a more general analysis of management's interventions on market prices. We postpone a discussion of the related literature on contingent capital to Section 1.1.

${ }^{3}$ The Black and Cox model is appropriate for our setting since banks liabilities (deposits) will most likely have staggered maturities (Ericsson and Reneby, 1998), and therefore monitoring occurs not only at maturity. Chen, Glasserman, and Nouri (2012) stress the need to introduce jumps (e.g. Duffie and Lando, 2001). However, our model setting can incorporate the effect of jumps through delayed bank seizing by the regulator (Section 2.1), as well as an extension of our model in which the audit frequency is discrete (Section 4.1).
} 
tant effects on financial stability. We focus on two channels: first, we quantify the reduction in default probability of issuing contingent capital instead of subordinated debt, second, we analyze the effect of contract design on risk-taking incentives.

For any level of leverage and asset volatility, a financial institution with contingent capital has a lower default probability than one with subordinated debt. In fact, for intermediate levels of asset risk, there is a significantly higher default probability for banks with subordinated debt instead of contingent capital. Not surprisingly, for relatively low asset risk the probabilities of default under the two alternative capital structures are both close to zero. The effectiveness of contingent capital as a stabilizing tool is thus most pronounced for intermediate and high levels of a bank's asset risk. The difference can be very large: for reasonable parameter values the default probability for subordinated debt is two to three times larger than if the bank issues contingent capital instead.

We next analyze the effect on risk-taking incentives of including contingent capital in the capital structure. Stockholders may be able to change the risk profile of the bank's assets in order to maximize the value of their own holding (Jensen and Meckling, 1976; Galai and Masulis, 1976). ${ }^{4}$ Regulators and policymakers are trying to understand the relationship between contingent capital, financial stability, and the risk-taking motivation of equity holders in financial institutions (Acharya, Cooley, Richardson, and Walter, 2009). If stockholders are motivated to continually increase or reduce asset risk, it may become either too high, one of the main reasons for the financial crisis, or too low, which may result in a credit freeze and a lack of lending by financial institutions. ${ }^{5}$ Furthermore, incentives that are sensitive to asset risk may reduce managements' attention to maximizing overall bank asset value. We identify contract terms that lead stockholders to have no desire to change the level of asset risk and thus show that contingent capital can reduce risk-shifting incentives present for a bank that

\footnotetext{
${ }^{4}$ Unlike firms in non-financial, unregulated industries, the primary creditors in a bank, the depositors, do not have sufficient incentives to monitor the bank, because of the implicit or explicit guarantees that are provided to commercial banks by national governments (see Saunders, Strock, and Travlos, 1990).

${ }^{5}$ Bebchuk, Cohen, and Spamann (2010) and Cheng, Hong, and Scheinkman (2010) provide examples of excessive risk-taking and link it to the recent financial crisis. However, there is also evidence that during the financial crisis many financial institutions shied away from risk thus contributing to the low levels of new loans (Maddaloni and Peydró, 2009).
} 
instead issues subordinated debt.

The two main contract terms are the conversion ratio and the conversion threshold. The conversion ratio is the percentage of the ownership in the post-conversion financial institution that contingent capital holders receive in case of conversion; previous shareholders receive the remainder. The conversion ratio can vary from 0 to 1 . A level of zero ("stock-friendly") means that in the event of conversion contingent capital holders receive nothing and equity holders are faced with a lower level of debt. In contrast, a conversion ratio of one ("coco-friendly") means that previous equity holders receive nothing and contingent capital holders become the post-conversion equity holders. ${ }^{6}$

We show that the conversion ratio has an important effect on risk-taking incentives. For low conversion ratios stockholders have a motivation to increase asset risk, while they are motivated to decrease asset risk for high conversion ratios. For intermediate conversion ratios the incentives for stockholders to change asset risk are small making them close to indifferent to the level of asset risk. The intuition for this effect is as follows: Increasing the level of asset risk makes conversion more likely. Conversion results in debt reduction but also in dilution of current stockholders. If dilution is small (low conversion ratio, "stock-friendly") current stockholders are motivated to increase risk while they are better off decreasing risk if dilution is large (high conversion ratio, "coco-friendly"). What we show is that for intermediate levels of the conversion ratio costs and benefits of higher asset volatility offset and incentives to risk-shift can be virtually eliminated.

The conversion threshold, the level of asset value at which a bond is converted into equity, has only a relatively minor effect on incentives. The contract term that remains the dominant factor is the conversion ratio. For example, if the conversion ratio is low, it is beneficial for management to increase risk. Different threshold levels do not change the direction of the incentives, they only lead to slightly stronger or weaker incentives. Similarly, for intermediate

\footnotetext{
${ }^{6}$ Interestingly, the conversion ratio, even though it varies across recently issued instruments, has tended to be low ("stock-friendly"). For example, Rabobank issued a security with a conversion ratio of 0. Lloyds Bank and Credit Suisse have issued contingent convertible bonds which are converted into the underlying stock at a relatively low or "stock-friendly" conversion ratio, where bondholders receive only a small share of the post-conversion equity.
} 
levels of the conversion ratio incentives remain small for different conversion thresholds. ${ }^{7}$ Thus, by choosing certain contingent capital contract terms ('well-designed' contingent capital), it is possible to achieve low risk-shifting incentives.

Well-designed contingent capital continues to result in virtually no risk-shifting incentives even in times of financial distress: The effect of the conversion ratio is robust to different levels of leverage. For intermediate levels of the conversion ratio there is little effect of leverage on risk-taking incentives. Consequently, even when a bank moves closer to financial distress the temptation to risk-shift does not increase substantially. In addition, a regulator either seizing banks as soon as there are early signs of distress (a high seizing threshold) or later on (a low seizing threshold) has practically no effect on risk-taking incentives.

A major benefit of introducing contingent capital is the reduction in risk-shifting incentives when compared to financial institutions with alternative capital structures. Comparing risk-taking incentives for a bank with contingent capital to ones with either only equity or with subordinated debt, we find a sharp reduction in risk-taking incentives for well-designed contingent capital. In contrast, equity holders in a bank with only equity are more motivated to increase asset risk. Though for the same asset risk and ratio of deposits to assets a bank with contingent capital and one with equity only have the same default probability (Admati, DeMarzo, Hellwig, and Pfleiderer, 2010), an all-equity financed bank continues to induce management to increase risk. Meanwhile, a bank with subordinated debt has both a higher default probability at the same level of asset risk and clear incentives to increase risk. Contingent capital may therefore have important advantages over both alternative capital structures.

A common belief is that the financial crisis was in substantial part the consequence of flawed executive compensation formulas that gave senior managers at major financial institutions perverse incentives to pursue short-term profits by accepting risk and high leverage (see Binder, 2010; Bebchuk and Spamann, 2010). We show that using equity-based compensation does not necessarily lead to undesirable incentives so long as the bank issues contingent capital. There may therefore be no need for additional changes to compensation.

\footnotetext{
${ }^{7}$ Although the conversion ratio is the dominant determinant of incentives, the exact level at which incentives are minimized may depend on the conversion threshold. This means that contingent capital design that intends to minimize risk-shifting motivation needs to take into account both parameters.
} 
We also briefly consider two other possibilities for affecting incentives. First, recent proposals have suggested using contingent capital as compensation. We find that such compensation can also be designed to achieve low risk-shifting motivation. ${ }^{8}$ Second, a recent proposal by Hart and Zingales (2011) links monitoring to credit default swap (CDS) contracts. In their proposal an increase in the CDS spread above a certain threshold will lead to a mandatory automatic increase in capital. However, a potential drawback of the proposal is that it may introduce strong incentives for equity holders to decrease asset risk to potentially undesirably low levels, something that we find not to be the case for contingent capital.

Our analysis suggests that the introduction of contingent capital will have two stabilizing effects on the banking sector. A reduction in default probability (for a given level of asset volatility) and the ability of well-designed contingent capital to virtually eliminate potentially inefficient incentives to increase risk. Indeed, French et al. (2010) point out in "The Squam Lake Report" that these two aspects - a reduction in financial institution default probability and a change in compensation structure that will reduce incentives for potentially excess risktaking - are important when aiming to stabilize the banking sector. We point out that welldesigned contingent capital may be able to achieve both by using one instrument.

The rest of the paper is organized as follows. We next briefly survey the literature on contingent capital. Section 2 presents the basic assumptions for the valuation of corporate liabilities of a bank with contingent capital in its capital structure and for a bank with subordinated debt. We provide closed-form solutions for the valuation of a bank's claims using option replication. Section 3 compares default probabilities for capital structures that either include contingent capital or subordinated debt. Section 4 analyzes the risk-taking motivation of stockholders for different terms of the contingent convertible bonds (conversion ratio and conversion threshold), leverage, regulatory seizing policy, and compares the effects on risk-taking of a bank with contingent capital and one with subordinated debt or equity only. Section 5 concludes.

\footnotetext{
${ }^{8}$ On December 3, 2010 Reuters reported that the investment banking arm of Barclays is leaning towards issuing contingent capital securities to employees as part of their 2010 deferred compensation.
} 


\subsection{Recent literature on contingent capital}

Flannery $(2002,2009)$, who introduces the idea of contingent capital for large financial institutions, considers a subordinated debt instrument that pays a fixed payment to its holders but converts automatically into equity when a certain stress-related trigger is breached. Importantly, conversion occurs at the market price of the bank's stock on the day of the conversion, a feature that may result in undesirable conversion scenarios and multiple equilibria. ${ }^{9}$ In an effort to address this issue, Sundaresan and Wang (2011) propose a contingent capital bond that pays a floating coupon. The number of shares issued at conversion multiplied by the trigger price equals the contingent capital bond's par value. Pennacchi, Vermaelen, and Wolff (2010) propose a coco with buyback options for equity holders and Duffie (2009) proposes a mandatory offering of new equity by banks facing financial distress.

Alternative proposals for the design of contingent capital have lead to work on valuation. Pennacchi (2010) compares several cases in a jump diffusion model. Albul, Jaffee, and Tchistyi (2010) obtain closed-form pricing expressions under the assumption that all debt has infinite maturity. Glasserman and Nouri (2011) suggest a conversion mechanism process that converts just enough debt to meet the capital requirement each time a bank's capital ratio reaches the minimum threshold. Our paper focuses on a tractable form of contingent capital with a closed-form solution that allows us to analyze the effect of contract design on incentives.

Other studies have also considered the effect of contingent capital on risk-taking incentives. Both Chen, Glasserman, and Nouri (2012) and Albul, Jaffee, and Tchistyi (2010) choose a setting based on Leland (1994), where bankruptcy is the result of an optimal decision made by equity holders. However, during the financial crisis banks were instead frequently seized by regulators, which is the framework we assume. Our study thus complements these two papers. Pennacchi (2010) and Berg and Kaserer (2012) consider the effect of contingent capital on risk-taking in the context of a Merton (1974) model, a setting in which default and conversion

\footnotetext{
${ }^{9}$ The market price of each corporate liability is a function of the ex-post possible payoffs that are contingent on the value of the underlying asset of the corporation. The fact that the payoff of a claim can be replaced by another payoff at some future time if its market value has touched some predetermined level may lead to an equilibrium in which conversion may not occur even if the corporation is in a bad standing and vice versa.
} 
can occur only at debt maturity. While this assumption is analytically tractable, it may be more appropriate for cases with very weak regulatory intervention policies and very weak mechanisms for monitoring of asset value by coco holders. In contrast to these studies, our focus is to discuss how well-designed contingent capital can minimize risk-taking motivation and to highlight the dual channels through which the presence of contingent capital can stabilize the banking sector, namely by reducing risk-shifting incentives and by a reduction in default probability.

Studies have also proposed other methods for capital provision in financial distress. Kashyap, Rajan, and Stein (2008) suggest that an insurer could receive a premium for agreeing to provide an amount of capital to the bank in case of a systemic crisis. The policy would pay out upon the occurrence of a 'banking systemic event,' for which the trigger would be some measure of aggregate write-offs of major financial institutions over a year-long period. Caballero and Kurlat (2009) suggest that the central bank could issue tradable insurance credits, which would allow holders to attach a central bank guarantee to assets on their balance sheet. A threshold level or trigger for systemic panic would be determined by the central bank.

In the next section we present a tractable proposed form of contingent capital with a finite maturity, a pre-determined conversion ratio, and a conversion trigger that is related to asset value. Our setup allows us to present in a straightforward way the effects of introducing contingent capital into a bank's capital structure, while leaving open the possibility of refinements, as discussed above. Furthermore, using the analytical solution allows us to examine the effect of contract design on default probability and risk-taking incentives.

\section{A model for pricing bank capital}

\subsection{Bank capital structure}

We consider a hypothetical bank with asset value denoted by $V .{ }^{10}$ To finance its assets, the bank issues three types of claims as part of its capital structure: a single zero-coupon deposit,

\footnotetext{
${ }^{10}$ To keep the notation as simple as possible, all variables without subscripts are present values.
} 
either contingent convertible or subordinated debt, and a residual equity claim. All the claims mature at time $T$, unless there is a security specific event previous to time $T$.

\subsubsection{Contingent convertible bonds}

We first consider the capital structure of a bank that issues contingent convertible bonds so that the capital structure includes deposits, coco, and equity.

The most senior claims in the capital structure are secured deposits with face value $F^{D}$. We assume that the government regulator will either seize the bank or force liquidation in the event of bank insolvency. Both of these events represent default which means that default occurs either at debt maturity, $T$, if the value of assets lies below the face value of the deposits, $F^{D}$, or if at any time $t$ previous to maturity $T$, that is $0<t<T$, the value of bank assets touches the default threshold $K^{D}$. We refer to such an event as early default $\tau_{D}<T$ where the event is defined as:

$$
\tau_{D}=\inf \left\{t>0 \mid V_{t} \leqslant K^{D}\right\}
$$

We assume that the default threshold $K^{D}$ is equal to $F^{D}(1-\gamma)$, where $0 \leqslant \gamma \leqslant 1$, which means that the threshold is located below the face value of deposits. This assumption follows Black and Cox (1976) and captures the fact that the regulator has limited ability to seize the bank at the moment it becomes insolvent either because of imperfect information due to discrete audit frequency (Duffie and Lando, 2001), or simply choosing a policy where banks are not immediately seized (Cetin, Jarrow, Protter, and Yildirim, 2004). We can think of the size of $\gamma$ as being related to the ability and willingness of the regulator to closely monitor and enforce bank solvency. ${ }^{11}$ Close monitoring may be costly and may be difficult in the case of complicated bank balance sheets, for example those holding complex or illiquid assets such as tranches of collateralized debt obligations (CDO) of pools of mortgage backed securities

\footnotetext{
${ }^{11}$ The depletion of the FDIC's Deposit Insurance Fund (DIF) during the financial crisis is likely a consequence of the difficulty faced by the regulator in shutting down banks exactly at the moment when asset value reaches the value of liabilities. See also Prescott (2011), who points out that, despite the policy of 'prompt corrective action' by the FDIC, during the crisis losses to the deposit insurance fund were substantial.
} 
(MBS). Figure 1 presents sample paths of asset value; default occurs either before maturity (1.C) or at maturity (1.B).

The second debt security in the capital structure is the contingent convertible bond with face value $F^{C}$ and market value $C$. It pays $F^{C}$ at maturity if there is no prior conversion event (Figure 1.A). In this case the stockholder is the residual claimant and receives $\left(V_{T}-F^{C}-F^{D}\right)$. Conversion occurs if at any time previous to maturity the value of the financial institution drops below the conversion threshold $K^{C}$, defined as:

$$
K^{C}=(1+\beta)\left(F^{C}+F^{D}\right)
$$

where $\beta(\beta \geqslant 0)$ measures the distance between the conversion threshold and the bank's book value of debt. A larger $\beta$ implies conversion at times of lower leverage and lower probability of financial distress.

If $V<K^{C}$ at any time before maturity, the coco is converted into equity (Figure 1.B). In this event the coco holder receives a share $\alpha(0 \leqslant \alpha \leqslant 1)$ of the equity and the previous shareholders receive the remaining $(1-\alpha)$. At maturity, the payoff to the coco holder is therefore equal to $\alpha\left(V_{T}-F^{D}\right)$ and the original stockholder receives $(1-\alpha)\left(V_{T}-F^{D}\right)$ unless default occurs, in which case both claimholders receive nothing (Figure 1.C). The time of conversion is defined as

$$
\tau_{C}=\inf \left\{t>0 \mid V_{t} \leqslant K^{C}\right\}
$$

We note that $\beta \geqslant 0$ implies that the event of conversion will always occur before the event of default, i.e. $\tau_{C} \leqslant \tau_{D}$. The payoff at maturity to the coco holders and to equity holders can be written as:

$$
\begin{aligned}
& C_{T}=F^{C} 1_{\left\{\tau_{C}>T\right\}}+\alpha \max \left\{\left(V_{T}-F^{D}\right), 0\right\} 1_{\left\{\tau_{C}<T<\tau_{D}\right\}} \\
& E_{T}=\left(V_{T}-F^{C}-F^{D}\right) 1_{\left\{\tau_{C}>T\right\}}+(1-\alpha) \max \left\{\left(V_{T}-F^{D}\right), 0\right\} 1_{\left\{\tau_{C}<T<\tau_{D}\right\}}
\end{aligned}
$$


where $1_{\psi}$ is an indicator function of the event $\psi$. Table 1 summarizes the payoffs to claimholders in the different possible cases.

\subsubsection{Subordinated debt}

Next, we define a capital structure that includes subordinated debt instead of coco. and thus consists of deposits, subordinated debt, and equity. Defining this capital structure allows us to compare the effects on default probability and risk-taking motivation of the stockholders for cases where the capital structure contains coco instead of subordinated debt.

The subordinated debt has face value $F^{B}$ and market value $B$. As in the previous case of coco in the capital structure, default occurs if the value of the bank's assets falls below the threshold $K^{D}$ at any time before maturity $T$. If this event occurs, the subordinated debt holder receives nothing. Default can also occur if at maturity the asset value lies below the

face value of total debt $\left(V_{T}<F^{D}+F^{B}\right)$. There is no mandatory conversion or increase in capital as a result of low asset value; instead, the subordinated debt holders have the ability to take legal action if at maturity the value of the financial institution is smaller than the sum of the face values of deposits and subordinated debt. This means that default can occur either if before maturity asset value falls below the threshold $K^{D}$ or if at maturity asset value is below the total face value of debt instruments $\left(F^{D}+F^{B}\right)$. Therefore, as long as $F^{B}$ is larger than zero, the default probability in the case of subordinated debt is, ceteris paribus, larger than in the case of coco.

The payoff to subordinated debt holders is equal to zero if the bank is taken over by the regulator before maturity $\left(\tau_{D}<T\right)$ or if at maturity the residual value of assets is below the value of deposits and there is no surplus to be paid to the subordinated debt holders $\left(V_{T}<F^{D}\right)$. If at maturity asset value lies between the total face value of debt and the face value of the deposits $\left(F^{D}<V_{T}<F^{D}+F^{B}\right)$, subordinated debt holders receive the residual assets of the financial institution after the deposit holders are paid in full. Otherwise, if there is no default, subordinated debt is paid in full $\left(F^{B}\right)$. The payoff can be summarized as:

$$
B_{T}=\left(\max \left\{V_{T}-F^{D}, 0\right\}-\max \left\{V_{T}-F^{D}-F^{B}, 0\right\}\right) 1_{\left\{\tau_{D}>T\right\}} .
$$


Finally, the equity holders' payoff at maturity, in the case that default has not occurred before that time $\left(\tau_{D}>T\right)$, is equal to the residual value of assets:

$$
E_{T}=\max \left\{V_{T}-F^{D}-F^{B}, 0\right\} 1_{\left\{\tau_{D}>T\right\}}
$$

If default occurs previous to maturity equity holders receive nothing. Table 2 reports the payoffs for the different states of the world.

\subsection{Valuation of bank liabilities with contingent capital or sub- ordinated debt}

\subsubsection{Valuation of claims when capital structure includes contingent capital}

We price each claim by replicating its payoff using a combination of different barrier options that all have closed form solutions. The appendix describes the payoffs and the pricing equations for all of the options that are used to replicate the different payoff functions.

We first consider the case of a capital structure with coco. The value of the deposits derives from future cash flows that may be received in the events of no default, early default, and default at maturity. ${ }^{12}$ Intuitively, the payoff to deposit holders at maturity is equal to the payoff of a zero coupon bond and a European put option, as pointed out by the seminal paper of Merton (1974). The difference in our case is that, since early default can occur, both options are path dependent.

The value in the case of early default is equal to $(1-\gamma) F^{D}$ units of a down-and-in digital barrier option, defined as $D B^{\operatorname{din}}\left(K^{D}\right)$. This option pays $\$ 1$ the first time before maturity that asset value hits the default threshold $\left(K^{D}\right)$ and nothing otherwise. The value in the case of no early default is replicated by using two down-and-out barrier options. If default does not occur at maturity, the payoff to the deposit holder is equal to the face value of the deposits $F^{D}$, and therefore the payoff can be replicated by $F^{D}$ units of a long position in a

\footnotetext{
${ }^{12}$ In calculating the market value of the deposits we abstract here from the potential payments by the deposit insurer in case of default. We can calculate the expected cost of insurance to the regulator in our framework but we omit this for the sake of brevity.
} 
down-and-out digital barrier option, defined as $D B^{\text {dout }}\left(K^{D}\right)$. If default occurs at maturity, the deposit holder receives the residual assets of the financial institution and therefore the loss can be replicated by using a down-and-out put option $P B^{\text {dout }}\left(K^{D}, F^{D}\right)$ with a strike price equal to the face value of the deposits $F^{D}$ and a barrier level equal to the default threshold $K^{D}$. Both options have down-and-out features since early default can occur. Assuming a constant interest rate $r$ the value of deposits can be expressed as:

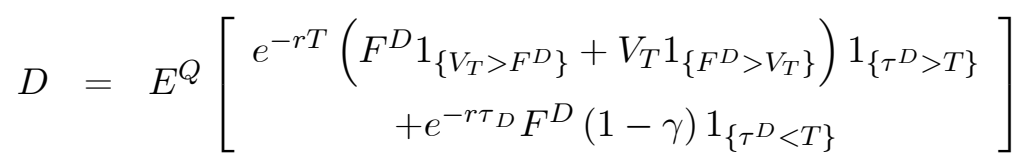

$$
\begin{aligned}
& D=F^{D}\left[D B^{\text {dout }}\left(K^{D}\right)+(1-\gamma) D B^{\text {din }}\left(K^{D}\right)\right]-P B^{\text {dout }}\left(K^{D}, F^{D}\right)
\end{aligned}
$$

where $E^{Q}[$.$] denotes the expectation under the risk-neutral measure Q$.

To price the coco we need to take into account three mutually exclusive events that affect its payoff. First, the value from the case of no conversion before maturity $T$, which is equal to $F^{C}$ units of a down-and-out digital barrier option with a barrier of $K^{C}$. The value contributed to the second possible event (conversion and no default) and to the third possible event (default where the coco holder receives nothing) are replicated by a spread position in two down-and-in barrier call options with the same strike, but with different barriers. The coco holder has a long position in $\alpha$ units of a down-and-in call option on the value of assets $C B^{\operatorname{din}}\left(K^{C}, F^{D}\right)$, with a strike price equal to the face value of deposits $F^{D}$ and a threshold level of $K^{C}$. However, if asset value falls further and touches the default threshold the equity becomes worthless and the coco holder receives nothing. To capture this payoff structure we add a similar but short position in a down-and-in call option $C B^{\operatorname{din}}\left(K^{D}, F^{D}\right)$ with the same terms except having a barrier at the default threshold. This means that if asset value touches $K^{D}$ the two option payoffs cancel each other. We can write the coco value as:

$$
\begin{aligned}
& C=E^{Q}\left[e^{-r T}\left(F^{C} 1_{\left\{\tau^{C}>T\right\}}+\alpha\left(V_{T}-F^{D}\right) 1_{\left\{\tau^{C}<T<\tau^{D}, V_{T}>F^{D}\right\}}\right)\right] \\
& C=F^{C} D B^{\text {dout }}\left(K^{C}\right)+\alpha\left(C B^{\text {din }}\left(K^{C}, F^{D}\right)-C B^{\text {din }}\left(K^{D}, F^{D}\right)\right) .
\end{aligned}
$$


The stock price is affected by the outcome of the same three mutually exclusive events as in the case of the coco: no early default and no conversion, no early default and conversion, and early default. The value of the stock can be expressed as follows:

$$
\begin{aligned}
& E=E^{Q}\left[e^{-r T}\left(\begin{array}{c}
\left(V_{T}-F^{C}-F^{D}\right) 1_{\left\{\tau^{C}>T\right\}} \\
+(1-\alpha)\left(V_{T}-F^{D}\right) 1_{\left\{\tau^{C}<T<\tau^{D}, V_{T}>F^{D}\right\}}
\end{array}\right)\right] \\
& E=C B^{\text {dout }}\left(K^{C}, F^{D}+F^{C}\right)+(1-\alpha)\left(C B^{\text {din }}\left(K^{C}, F^{D}\right)-C B^{\text {din }}\left(K^{D}, F^{D}\right)\right)
\end{aligned}
$$

where $C B^{\text {dout }}\left(K^{C}, F^{D}+F^{C}\right)$ is a down-and-out call option. This option is a European call option on the underlying bank asset value that pays off at maturity only if the asset value does not touch the conversion threshold $K^{C}$ before maturity. In case of conversion, equity value is divided between the original stockholders, who receive $(1-\alpha)$, and the coco holders, who receive a fraction $\alpha$. Therefore, as in the case of the coco we use a position in a down-and-in call option to take into account the stream of cash flows at the event of early conversion; the number of option units is equal to $(1-\alpha)$.

\subsubsection{Capital structure with subordinated debt}

Figure 2 presents sample paths for the different scenarios in the case of a capital structure with subordinated debt. Since the event of conversion does not affect the payoff of the deposit holders there is no difference between the pricing of deposits in a bank with coco as part of its capital structure and an all else identical bank that does not have the conversion option.

The potential future cash flows to the subordinated debt holder depend on two mutually exclusive events: no default until maturity (Figure 2.B) and early default (Figure 2.C); Figure 2.A show a sample path with no default. As in the case of coco, at the event of early default, when the value of assets is equal to the default threshold $K^{D}$, the subordinated debt holder receives nothing. In the case that default does not occur until debt maturity the payoff to the subordinated debt holders can be replicated by two options - a long position in a down-and-out call option with a strike price equal to the face value of the deposits and a short position in a similar option but with a higher strike which is equal to the total face value of the debt 
instruments, $\left(F^{D}+F^{B}\right)$. If the value of assets touches the default threshold before maturity the subordinated debt holders receive nothing, which means that both options are down-andout barrier options with the same barrier of $K^{D}$. The replicating options are identical to the Black and Cox (1976) framework for pricing subordinated debt and can be expressed as follows:

$$
\begin{aligned}
B & =e^{-r T} E_{t}^{Q}\left[\begin{array}{c}
F^{B} 1_{\left\{\tau^{D}>T, V_{T} \geqslant F^{B}+F^{D}\right\}} \\
+\max \left(V_{T}-F^{D}, 0\right)
\end{array}\right] 1_{\left\{\tau^{D}>T,\left(F^{B}+F^{D}\right)>V_{T} \geqslant F^{D}\right\}} \\
B & =C B^{\text {dout }}\left(K^{D}, F^{D}\right)-C B^{\text {dout }}\left(K^{D}, F^{D}+F^{B}\right) .
\end{aligned}
$$

The value of equity can be replicated by a down-and-out call option. While in the case of coco a similar option is used for replicating the payoff at the event of no early conversion, in the case of subordinated debt the barrier is equal to the default threshold and not to the conversion threshold. The present value of the payoff can be written as:

$$
\begin{aligned}
E & =e^{-r T} E_{t}^{Q}\left[\max \left(V_{T}-F^{D}-F^{B}, 0\right)\right] 1_{\left\{\tau^{D}>T\right\}} \\
E & =C B^{\text {dout }}\left(K^{D}, F^{B}+F^{D}\right) .
\end{aligned}
$$

\subsection{Firm value process}

The pricing of the different liabilities which compose the capital structure of a bank depends on the assumed stochastic process of the underlying asset. We assume that the dynamics of the bank's assets follow a simple Geometric Brownian Motion. This assumption is consistent with most existing structural models (Merton, 1974; Black and Cox, 1976; Brennan and Schwartz, 1978; Longstaff and Schwartz, 1995; Leland, 1994; Ericsson and Reneby, 1998) and with models for pricing a bank's claims (Albul, Jaffee, and Tchistyi, 2010; Glasserman and Nouri, 2010; and Sundaresan and Wang, 2011). ${ }^{13}$ The assumption also has the advantage of having closed form solutions, which allows us to analyze in a straightforward way the sensitivity of the bank's

\footnotetext{
${ }^{13}$ Pennacchi (2010) instead considers a jump-diffusion formulation for the firm's underlying asset.
} 
stock price to changes in the value of asset risk. The closed form solutions for the barrier options we use are developed by Merton (1973) and Rubinstein and Reiner (1991).

\section{Default probability}

\subsection{Contingent capital vs. subordinated debt}

Policymakers and regulators are interested in monitoring the default probability of a financial institution due to the potentially harmful effect of default on the real economy. The default probability of a bank with subordinated debt as part of its capital structure is always equal to or greater than the default probability of a bank with contingent capital, since the subordinated debt holders can force default at maturity if their claims are not fully met. In contrast, the contingent convertible bonds would always be converted into stock before the event of default and the regulator is the only entity that can force default at maturity.

The probability of default of a bank with subordinated debt is composed of two mutually exclusive events. Either before maturity asset value falls below the default threshold $K^{D}$, or at maturity the value of assets is below the total face value of $\operatorname{debt}\left(F^{D}+F^{B}\right)$. Thus, the probability of default can be expressed as follows:

$$
P D(B)=\operatorname{Pr}\left(\tau^{D}<T\right)+\operatorname{Pr}\left(V_{T}<\left(F^{D}+F^{B}\right) \mid \tau^{D}>T\right) .
$$

The probability of default for a bank with coco is also composed of two mutually exclusive events. However, if default has not occurred until debt maturity, only the regulator can enforce default when the value of the bank's assets lies below the face value of the deposits. The probability of default of a bank with a capital structure that includes coco can be written as:

$$
P D(C)=\operatorname{Pr}\left(\tau^{D}<T\right)+\operatorname{Pr}\left(V_{T}<F^{D} \mid \tau^{D}>T\right)
$$

As long as there is subordinated debt in the capital structure $\left(F^{B}\right.$ is positive), the default 
probability in the case of subordinated debt is, ceteris paribus, larger than in the case of coco. The difference is equal to

$$
P D(B)-P D(C)=\operatorname{Pr}\left(\left(F^{D}+F^{B}\right)>V_{T}>F^{D} \mid \tau^{D}>T\right)
$$

\subsection{Base case parameters}

In order to quantify the effect of introducing contingent capital into a bank's capital structure we choose base case parameter values and then perform sensitivity analysis around these values.

We assume that the bank has a capital structure composed of deposits with face value $F^{D}$, which is normalized to 100 , contingent capital with a face value $F^{C}$, which is equal to $3 \%$ of the face value of the deposits, and time to maturity for both instruments of one year $(T=1)$. We define the quasi leverage ratio as the present discounted value of book liabilities divided by current asset value, $L R=\frac{\left(F^{D}+F^{C}\right) e^{-r T}}{V_{t}}$. Setting leverage $L R=0.93$ then results in a level of bank assets equal to 108.02 if the risk-free rate is equal to $2.5 \%$. The bank asset risk $\sigma$, is set equal to $5 \%$; the coco conversion ratio $\alpha$ is equal to 0.5 , and $\beta=1 \%$ so that the conversion threshold $K^{C}$ is located $1 \%$ above the total face value of the two debt instruments - conversion occurs before debt maturity at the first time that the value of the bank's assets is equal to $(1+\beta)$ times the total face value of the debt, $\left(F^{D}+F^{C}\right)$. The policy of the regulator is to seize the bank the first time that the value of assets is $3 \%$ below the face value of the deposits $(\gamma=3 \%)$. Table 3 summarizes the parameters. The appendix provides sources and discussion justifying the parameters used in the base case of our analysis.

For the base case parameter values the 1-year risk neutral default probability for a bank with coco is $2.3 \%$ and for a bank with subordinated debt is $7.7 \%$. The substantially lower default probability of a bank with coco is a reflection of the stabilizing effect that coco has on the capital structure. In the case of a deterioration in asset value instead of default there is an automatic provision of capital. ${ }^{14}$

\footnotetext{
${ }^{14} \mathrm{~A}$ couple of observations are useful when interpreting the base case default probabilities. First, we report risk neutral probabilities, which are larger than real default probabilities as long as there is a positive risk premium. Second, we are interested primarily in the relative magnitudes of the default
} 


\subsection{Sensitivity of default probability to parameter values}

While it is clear that, ceteris paribus, the probability of default of a bank with coco is equal to or lower than that of a bank with subordinated debt, the difference between the probabilities is affected by the leverage ratio and the level of asset risk. Table 4 performs sensitivity analysis with respect to asset volatility (1\% to $9 \%)$ and leverage (0.91 to 0.95$)$.

For low levels of asset volatility the probabilities of default under the two alternative capital structures are almost identical. In both cases default probabilities are close to zero when asset risk is equal to $1 \%$ for any leverage ratios between 0.91 and 0.95 . If asset risk is low, a large deterioration in asset value is unlikely which means that the effect of coco in the capital structure is small. In contrast, differences in default probabilities are much larger for higher levels of asset volatility. When asset risk is equal to $5 \%$, the difference in default probability is equal to $2.4 \%, 5.4 \%$, and $9.8 \%$ for leverage ratios of $0.91,0.93$, and 0.95 respectively. For intermediate levels of asset volatility, including contingent capital can thus significantly reduce the default probability. For high levels of volatility and leverage, default probabilities are high in both cases, though they remain much lower if coco is included. Introducing coco into the capital structure therefore may have important stabilizing effects on banks, which are pronounced in particular for intermediated values of asset risk.

\section{Risk-taking motivation}

If contingent capital is introduced, how should it be structured? We now address this question. In addition to affecting the default probability, introducing contingent capital into a bank's capital structure can affect the risk-taking motivation of stockholders. While in the previous section we assumed that asset risk is exogenous, we now assume that the bank's management can determine the level of asset risk and analyze the effect of contingent capital on risk-taking motivation.

probabilities which show that the default probability in the case of coco is significantly smaller than in the case of subordinated debt. 


\subsection{Risk-taking with equity-based compensation}

We assume that the dominant component of the executive pay package that is sensitive to asset risk is equity-based compensation and that management chooses the level of asset risk that maximizes the value of stock, for example by choosing the riskiness of the bank's lending activities. ${ }^{15}$ We analyze the risk-taking motivation under different terms of the coco contract, leverage ratios, as well as different capital structures (subordinated debt or additinal equity instead of coco). We also demonstrate that our results are robust to assuming a discrete audit frequency, different regulatory seizing policies, and to a pay package that consists of compensation in the form of coco. Consistent with our findings, Sundaresan and Wang (2011), Pennacchi (2010), and Albul et al. (2010) also suggest that a particular choice of conversion ratio may have implications for risk-shifting. However, these studies do not analyze optimal coco design or compare incentives to financial institutions with alternative capital structures.

In analyzing bank risk-taking incentives, we assume that asset volatility lies in a range around 5\%, consistent with Mehran and Rosenberg (2008), who find that the average asset risk of banks in a large sample is equal to 5.3\%. The size of the cross-sectional standard deviation around this average is equal to $2.2 \%$. When considering management's incentives to increase or decrease asset volatility we assume that banks' asset volatility lies within about two standard deviations of the mean level of volatility. Specifically, we assume that financial institution asset volatility lies between $1 \%$ and $9 \%$. We might view levels of volatility outside of this range as being difficult to achieve due to the availability of a limited set of lending opportunities and projects (John, Saunders, and Senbet, 2000). In addition, levels of asset volatility that lie substantially above the normal range may draw additional attention from the regulator who will try to restrict such levels of risk-taking.

\footnotetext{
${ }^{15}$ We thus analyze here the incentives that management has to either increase or decrease risk given the existing contract. In theory it is possible to formulate a pricing model that takes into account that equity holders will maximize equity value by choosing asset volatility. We do not consider such a setup but instead analyze ex-post risk-shifting by management. We note that this approach, which allows for transfers of wealth from debt to equity, is standard in the literature.
} 


\subsubsection{Contingent capital design (conversion ratio and threshold)}

The conversion terms of the coco have important effects on the risk-taking motivation of the stockholders, since the potential conversion event introduces additional complexity compared to capital structures with subordinated debt or with stock and deposits only. As the level of asset risk increases, the probability of touching the conversion threshold increases. This event has two opposing effects on equity value:

1. Equity value decreases, since in case of conversion stockholders lose some of their position to coco holders.

2. Equity value increases, since leverage decreases in case of conversion.

Figure 3 presents the effect of the conversion ratio $(\alpha)$ on the risk-taking motivation of the stockholder. All else equal, the value of the stock decreases as the conversion ratio increases. However, the stockholder's choice of asset risk strongly depends on the conversion ratio. For a relatively low ("stock-friendly") conversion ratio the value of the stock increases with asset risk. Intuitively, an increase in asset risk results in a larger increase in equity value due to the potential decrease in leverage at conversion than the loss of equity value due to stock dilution at conversion. The reverse relationship may exist for a relatively high ("coco-friendly") conversion ratio. When the conversion ratio is relatively low $(\alpha=0$ or 0.25$)$, the value of the stock increases with asset risk and when the ratio is relatively high $(\alpha=0.75$ or 1$)$, the value decreases with asset risk. Importantly, the value of the stock is almost insensitive to asset risk for intermediate levels of the conversion ratio. For example, the value of the stock is close to constant with respect to asset risk when the conversion ratio is equal to $50 \%$.

These results have important effects on the optimal behavior of an equity holder who tries to maximize the value of stock by controlling asset risk. For a relatively low conversion ratio the equity holder will choose the maximum possible level of asset risk; faced with a high conversion ratio, management will do the opposite. For some intermediate level of the conversion ratio the stockholder may be indifferent to asset risk, since the components that affect the value of equity, as presented above, offset each other. From the point of view of a regulator, intermediate levels of the conversion ratio may be preferable. Strong risk-shifting incentives may lead to 
either very high or very low levels of asset risk, both of which are likely undesirable since they may lead either to excessive risk or sub-optimally low levels of risky lending. A lack of strong risk-shifting incentives may therefore be optimal and, as we show, also achievable if the bank issues contingent capital.

Figure 4 shows the effect on risk-taking incentives of changing the conversion threshold, the level of asset value at which conversion takes place. We find that the conversion threshold has little impact on the relationship between incentives and the conversion ratio, which is the dominant factor affecting risk taking motivation. Figure 4 shows the sensitivity of the stock price for three levels of $\beta(0.5 \%, 1.5 \%, 2.5 \%)$, the percentage difference between asset value and the conversion threshold. We report equity value as a function of asset risk for three levels of the conversion ratio $(\alpha=0.1,0.5,0.9)$, each time considering the effect of varying the conversion threshold. Figure 4.A shows that when the conversion ratio is relatively low (equal to 0.1 , "stock friendly") stockholders will try to choose the maximum level of asset risk for any level of the conversion threshold. Figure 4.C considers a conversion ratio that is relatively high (equal to 0.9, "coco-friendly"). In this case the relationship between the stock value and asset risk is downward sloping for all three conversion thresholds; thus stockholders prefer the minimum level of asset risk. For intermediate levels of the conversion ratio, risk-taking incentives remain small for the different conversion ratios. Figure 4.B presents the sensitivity of the stock price to asset risk for a conversion ratio of 0.5 , for which the effect of asset risk on equity value is small for all three levels of the conversion threshold.

Since there are likely costs associated with a change in the composition of a bank's loan portfolio, we assume that stockholders need reasonably large incentives to induce them to actively engage in changing the financial institution's risk profile. Specifically, we classify incentives as weak (or 'indifferent') if the difference between stock value for high and low levels of risk is smaller than $0.5 \%$ of asset value. In such cases costs associated with risk-shifting are unlikely to outweigh the quite modest benefits and therefore will most likely make changes in asset risk not worthwhile. For a conversion ratio of 0.5 (Figure 4.B) management is indifferent between high and low levels of asset volatility for the three levels of the conversion threshold. 
Table 5 summarizes the asset risk choice of the stockholders for different terms. If stockholders have strong incentives to choose high or low levels of risk we report 'Maximum' or 'Minimum'; if incentives are weak (a change of asset volatility from $1 \%$ to $9 \%$ causes a change in the stock price of less than $0.5 \%$ of asset value) the table reports 'Indifferent,' The results in the table emphasize the importance of contingent capital design. The stockholders are indifferent with respect to the level of asset risk when the conversion ratio is equal to $50 \%$ and the conversion threshold lies between $0 \%$ and $2 \%$. For high levels of the threshold $(\beta=2 \%)$ the conversion ratio for which stockholders are indifferent is equal to $40 \%$ or $50 \%$, while for low levels of the conversion threshold $(\beta=0 \%)$ incentives are low for levels of the conversion ratio between $50 \%$ and $80 \%$. Thus, for all conversion thresholds, levels of indifference exist for an intermediate level of the conversion ratio, though the range of conversion ratios for which incentives are small depends on the conversion threshold.

\subsubsection{Leverage and risk-taking}

It is important to examine whether or not the effect of contingent capital on incentives changes across different environments (e.g. good times: low leverage ratio, and bad times: high leverage ratio). We find that the effect of issuing coco on risk-taking is very stable across different levels of leverage.

In Figure 5 we consider three levels of leverage $(L R=91 \%, 93 \%, 95 \%)$ and find that the dominant factor that determines incentives is the conversion ratio, similar to the effect on risktaking motivation of varying the conversion threshold. Figures 5.A and 5.C show that for all levels of leverage conversion ratios that are relatively high $(\alpha=0.9)$ or relatively low $(\alpha=0.1)$ result in relationships between asset risk and stock value that are upward and downward sloping respectively. As leverage increases the value of the stock becomes more sensitive to asset risk but the direction of the incentives remains the same. In Figure 5.B the conversion ratio is set equal to 0.5 . For this conversion ratio the sensitivity of equity value to asset risk is small for all three levels of leverage. Thus for an intermediate level of the conversion ratio the value of the stock is insensitive to asset risk for different levels of leverage.

To summarize, across both different conversion thresholds and leverage ratios, the primary 
determinant of incentives is the conversion ratio. The intuition is that only the conversion ratio affects the distribution of value in the event of conversion. Therefore, while the conversion threshold and leverage affect the overall likelihood of conversion taking place, they do not affect whether or not making conversion more likely is beneficial for stockholders.

\subsubsection{Different regulatory seizing policies}

We also consider differences in regulatory seizing policies and monitoring abilities. Our setup allows us to compare incentives for different levels of asset value at which the regulator seizes the bank. In our model the level at which the bank is seized is measured by the percentage difference between the par value of the deposits and the value of the bank's assets at which seizing occurs (the parameter $\gamma$ ). Figure 6 presents the value of stock versus asset risk for different regulatory seizing policies $(\gamma=1 \%, 3 \%, 5 \%)$. For all three levels the stock value is stable across different levels of asset risk. Specifically, moving from asset risk of $1 \%$ to $9 \%$ leads to only very small changes in equity value, which lie below $0.5 \%$ of asset value and which we therefore classify as not large enough to induce equity holders to change asset volatility. Regulators can be differentiated according to their ability and willingness to seize a bank in a financial distress. Our results show that the terms of the coco, which lead to stable incentives that minimize stockholder risk-shifting motivation, do not need to be adjusted to different seizing policies.

\subsubsection{Benefits of contingent capital: Comparison to other capital structures}

Having shown that well-designed contingent capital can virtually eliminate risk-taking incentives, the next question is if these incentives are more favorable than if financial institutions had alternative capital structures. We therefore consider risk-taking incentives for a bank that issues subordinated debt and one with only equity and deposits.

Figure 7 graphs equity value against asset risk for banks that are identical to our previous analysis (same base case parameter values), expect that they have capital structures that instead of contingent capital include subordinated debt (Figure 7.A) and only equity (Figure 7.B) in their capital structure. As before, we consider different levels of leverage 
$(L R=91 \%, 93 \%, 95 \%)$

Importantly, in contrast to stockholders in a bank with contingent capital, stockholders in a bank with subordinated debt are motivated to increase asset risk. Risk-shifting incentives are present for all three leverage ratios and the sensitivity of the stock price to asset risk increases with leverage (Figure 7.A). Of course, these patterns are consistent with the classic risk-shifting intuition associated with high levels of debt (Jensen and Meckling, 1976; Galai and Masulis, 1976). We also note that the higher risk-shifting incentives associated with higher leverage are in contrast to the case of contingent capital (discussed in Section 4.1.2 above), where financial institutions in financial distress do not experience large increases in risk-taking motivation.

While the typical capital structure of large financial institutions is composed of deposits, stocks and subordinated debt, one criticism raised against contingent capital is the claim that a capital structure which includes only deposits and stock has the same probability of default as a structure which includes coco, and that there is thus no advantage of introducing coco into a bank's capital structure (Admati et al., 2010). In both cases default occurs only if the bank is seized before maturity or if at maturity asset value lies below the face value of deposits. Indeed, for the same level of risk, an equity-only and a bank with coco have the same probability of default.

However, risk-taking incentives also play a role. Figure 7.B shows the risk-taking motivation of stockholders in a bank with a capital structure that includes deposits and equity only. In this case, the value of the stock increases with asset risk for any level of leverage and thus the stockholders are motivated to increase asset risk to the highest possible level. As in the case of subordinated debt, risk-shifting incentives are higher for higher levels of leverage. If changes in volatility are possible, the default probability of the bank with equity and deposits will therefore be higher compared to a bank with a well-designed coco that has no strong incentives for risk-shifting.

To summarize, risk-shifting incentives are present both if the bank's capital structure (in addition to deposits) includes either only equity or both equity and subordinated debt. Both cases then may be inferior to a capital structure that includes well-designed contingent capital. 


\subsubsection{Discrete audit frequency}

The conversion of contingent convertible bonds, following current market practice, occurs when the value of assets falls below the conversion threshold. We now consider what happens if asset value cannot be observed continuously. This assumption may be more reasonable given that some of the liabilities of a financial institution include untraded assets and that asset value is at least partly based on accounting data, proxies for which will be available only at lower than continuous frequencies. In addition, comparison of asset value to the conversion threshold may occur only at discrete intervals, e.g. once a day.

We consider the effect on the risk-taking motivation of monitoring the conversion threshold at discrete intervals. We use a straightforward approximation from Broadie, Glasserman and Kou (1997) to price the relevant barrier options discussed in Section 2. Figure 8.A presents the value of the stock for both continuous and monthly monitoring frequencies. As before, we set the distance between the conversion threshold and the total face value of debt as $\beta=1 \%$. In the case of continuous monitoring, the stockholder has a very low motivation for risk-shifting, since the difference between the maximum value of stock and the minimum value is equal to only $0.18 \%$ of asset value. However, we find that audit frequency affects incentives: In the case of monthly monitoring, the stockholder has a slight incentive to increase risk, though it still remains low. The difference between the maximum and minimum value of stock is now equal to $0.57 \%$ of asset value, a value only slightly above the level we classify as 'indifferent' in Table 5.

Figure 8.B shows that risk-shifting incentives can once again be reduced to below $0.5 \%$ by choosing a slightly higher conversion threshold. At a level of $\beta=3 \%$ the motivation for risk-shifting when monitoring is done monthly is very low. The difference between the maximum and the minimum value of the stock is now $0.21 \%$ of the value of assets. What this means is that, in the case where only discrete audit is possible, the terms of the contract can be adjusted in order to virtually eliminate risk-taking motivation resulting from equity-based compensation. 


\subsection{Risk-taking with coco-like compensation}

The typical compensation of managers in financial institutions is composed of equity-based compensation and therefore the analysis of the sensitivity of the stock price to asset risk is appropriate when trying to understand executive risk taking motivation (DeYoung et al., 2010).

Another possibility that has been proposed and recently introduced by Barclays is to replace conventional equity-based compensation with coco-like compensation. Given the recent interest we briefly explore the risk-taking motivation of a bank manager for whom coco is a major part of the compensation package, and who will be trying to maximize the value of compensation by changing the level of bank asset risk accordingly.

Figure 9 graphs coco value against asset risk for different levels of the conversion ratio. We find, as in the case of contingent capital, that the risk-taking motivation created by coco compensation depends on the terms of the coco. A high conversion ratio motivates the manager to take the maximum possible level of asset risk, while a low conversion ratio results in low asset risk. The reason is that a high ("coco-friendly") conversion ratio means that a higher level of risk makes conversion - which from the point of view of the coco holder is favorable - more likely. For example, when the conversion ratio is equal to 0.75 or 1 , bank managers, who hold coco, are motivated to take the maximum possible level of asset risk. A reverse motivation is present when the conversion ratio is low and equal to 0 or 0.25 . In such cases managers would try to take the minimum level of asset risk due to the positive relationship between asset risk and coco price. For a conversion level of $50 \%$ the value of the coco is insensitive to asset risk and managers are indifferent to the level of asset risk. Coco-like compensation can therefore minimize the risk-taking motivation of the manager. However, as discussed previously, coco compensation is not necessary to eliminate risk-taking motivation. All that is needed is for the capital structure to include well-designed contingent capital. In that case equity-based compensation results in virtually no incentive for managers to shift risk. 


\subsection{Monitoring default risk and risk-taking incentives}

Finally, we briefly consider a recent proposal by Hart and Zingales (2011) to track the credit default swap (CDS) spread of financial institutions. They propose a mechanism in which banks are required to raise additional capital in order to keep the CDS spread below a certain threshold. The idea is that a regulator, by observing market perceptions through market prices, can choose to directly monitor the risk-neutral default probability of the financial institution. However, in such a setting, it may be optimal for management to choose to reduce asset volatility. As discussed in Section 3, the risk neutral default probability decreases with asset volatility (see Table 4). Therefore, introducing a CDS spread threshold may lead to potentially inefficiently low levels of bank asset volatility and an associated credit crunch for riskier projects, even though these may be promising. These incentives are in contrast to those of bank management in the case of equity-based compensation and well-designed contingent capital in the capital structure.

\section{Conclusion}

In this paper we propose a tractable model of contingent capital (coco): subordinated debt that converts into common equity if a pre-determined threshold is reached before maturity. We provide closed-form solutions for the contingent capital price and other bank liabilities, and investigate the effect of issuing contingent capital on risk-taking motivation and default probability.

Contingent capital may be effective in stabilizing the banking sector. There are two important channels through which contingent capital can achieve a reduction in risk. First, banks that issue contingent capital instead of subordinated debt are significantly less likely to default. Second, contingent capital may be an effective tool that can influence bank management with equity-based compensation to refrain from increasing risk.

We show that contingent capital design (in particular the conversion ratio, the fraction of post-conversion common equity that contingent capital holders receive) has an important impact on risk-taking motivation. For relatively low ("stock-friendly") conversion ratios stock- 
holders have an incentive to increase asset risk, while a high ("coco-friendly") conversion ratio leads to a desire to reduce risk. Importantly, for intermediate levels of the conversion ratio, incentives to change risk are virtually eliminated. The presence of contingent capital means that an increase in risk may lead to conversion thus reducing equity holders' stake in the company. Such incentives may be beneficial since strong incentives to either increase or decrease risk can result in equity holders focusing primarily on project risk instead of encouraging banks to make the best possible investment decisions. It is therefore possible to create contingent capital contract terms that may be able to cancel out the adverse effects of equity-based compensation.

The presence of contingent capital may also reduce risk-taking incentives relative to two important benchmarks: replacing contingent capital with subordinated debt or with additional equity. We show that risk-taking incentives for a bank with well-designed contingent capital are smaller than both of these. Furthermore, incentives in a bank with contingent capital remain low even when a bank enters financial distress, while incentives to risk-shift increase with leverage for banks with subordinated debt or with equity only financing. Incentives also remain close to unaffected by different regulatory seizing policies (the level of bank losses at which the regulator takes over the institution), contingent capital does not lose its favorable characteristics if auditing is only possible at discrete intervals, and incentives may be more favorable than tracking bank CDS spreads.

During the recent financial crisis banks were severely undercapitalized and had to be bailed out. We show that introducing well-designed contingent capital into banks' capital structures represents a possibility to substantially reduce incentives to increase bank risk, decrease the bank failure rate, and reduce the need for costly provision of capital. 


\section{Appendix}

\section{A Option building blocks and pricing equations}

We provide here the pricing formulas of the five barrier options that serve as building blocks for the valuation of the bank's liabilities. The formulas are derived by Merton (1973) and Rubinstein and Reiner (1991).

Following the Black and Scholes (1973) assumptions, the risk-free interest rate is constant over time and equal to $r$. The value of assets, denoted by $S$, is well described under the risk neutral probability by the following stochastic differential equation:

$$
\frac{d S}{S}=r d t+\sigma d W
$$

where $W$ is a standard Brownian motion, and $\sigma$ is the instantaneous constant standard deviation of the asset's rate of return. All options expire at time $T$, have a strike price of $K$ and a barrier level of $H$.

1. Down-and-in call option: If $S$ (the underlying asset) reaches the barrier $H$, the option becomes a vanilla European call option with strike price $K$ and maturity $T$. If $S$ does not reach the barrier $H$ the option expires worthless. The value of the option with a barrier that is strictly larger than the strike price is:

$$
\begin{aligned}
C B^{d i n}= & S N\left(d_{1}\right)-K e^{-r T} N\left(d_{2}\right)+S\left(\frac{H}{S}\right)^{\left(\frac{2 r}{\sigma^{2}}+1\right)} N\left(d_{5}\right) \\
& -K e^{-r T}\left(\frac{H}{S}\right)^{\left(\frac{2 r}{\sigma^{2}}-1\right)} N\left(d_{6}\right)-S N\left(d_{3}\right)+K e^{-r T} N\left(d_{4}\right)
\end{aligned}
$$

where $N($.$) denotes the standard normal cumulative probability distribution function.$ The value of a down-and-in call option with a barrier which is smaller than the strike price is:

$$
C B^{d i n}=S\left(\frac{H}{S}\right)^{\left(\frac{2 r}{\sigma^{2}}+1\right)} N\left(d_{7}\right)-K e^{-r T}\left(\frac{H}{S}\right)^{\left(\frac{2 r}{\sigma^{2}}-1\right)} N\left(d_{8}\right)
$$


2. Down-and-out call option: If $S$ does not reach the barrier $H$, the option becomes a vanilla European call option with strike price $K$ and maturity $T$. If $S$ reaches the barrier $H$ the option expires worthless. The value of the option with a barrier that is strictly larger than the strike price is:

$C B^{\text {dout }}=S N\left(d_{3}\right)-K e^{-r T} N\left(d_{4}\right)-S\left(\frac{H}{S}\right)^{\left(\frac{2 r}{\sigma^{2}}+1\right)} N\left(d_{5}\right)+K e^{-r T}\left(\frac{H}{S}\right)^{\left(\frac{2 r}{\sigma^{2}}-1\right)} N\left(d_{6}\right)$.

The value of a down-and-out call option with a barrier which is strictly smaller than the strike price is:

$C B^{\text {dout }}=S N\left(d_{1}\right)-K e^{-r T} N\left(d_{2}\right)-S\left(\frac{H}{S}\right)^{\left(\frac{2 r}{\sigma^{2}}+1\right)} N\left(d_{7}\right)+K e^{-r T}\left(\frac{H}{S}\right)^{\left(\frac{2 r}{\sigma^{2}}-1\right)} N\left(d_{8}\right)$.

3. Down-and-out put option: If $S$ does not reach the barrier $H$, the option becomes a vanilla European put option with strike price $K$ and maturity $T$. If $S$ reaches the barrier $H$ the option expires worthless. The value of the option with a barrier that is strictly smaller than the strike price is:

$$
\begin{aligned}
P B^{\text {out }}= & S N\left(d_{1}\right)-K e^{-r T} N\left(d_{2}\right)-S\left(\frac{H}{S}\right)^{\left(\frac{2 r}{\sigma^{2}}+1\right)} N\left(d_{5}\right)+K e^{-r T}\left(\frac{H}{S}\right)^{\left(\frac{2 r}{\sigma^{2}}-1\right)} N\left(d_{6}\right) \\
& -S N\left(d_{3}\right)+K e^{-r T} N\left(d_{4}\right)+S\left(\frac{H}{S}\right)^{\left(\frac{2 r}{\sigma^{2}}+1\right)} N\left(d_{7}\right)-K e^{-r T}\left(\frac{H}{S}\right)^{\left(\frac{2 r}{\sigma^{2}}-1\right)} N\left(d_{8}\right)
\end{aligned}
$$

where

$$
\begin{gathered}
d_{1}=\frac{\ln \left(\frac{S}{K}\right)+T\left(r+\frac{\sigma^{2}}{2}\right)}{\sigma \sqrt{T}} \quad d_{2}=\frac{\ln \left(\frac{S}{K}\right)+T\left(r-\frac{\sigma^{2}}{2}\right)}{\sigma \sqrt{T}} \\
d_{3}=\frac{\ln \left(\frac{S}{H}\right)+T\left(r+\frac{\sigma^{2}}{2}\right)}{\sigma \sqrt{T}} \quad d_{4}=\frac{\ln \left(\frac{S}{H}\right)+T\left(r-\frac{\sigma^{2}}{2}\right)}{\sigma \sqrt{T}} \\
d_{5}=\frac{\ln \left(\frac{H}{S}\right)+T\left(r+\frac{\sigma^{2}}{2}\right)}{\sigma \sqrt{T}} \quad d_{6}=\frac{\ln \left(\frac{H}{S}\right)+T\left(r-\frac{\sigma^{2}}{2}\right)}{\sigma \sqrt{T}} \\
d_{7}=\frac{\ln \left(\frac{H^{2}}{S K}\right)+T\left(r+\frac{\sigma^{2}}{2}\right)}{\sigma \sqrt{T}} \quad d_{8}=\frac{\ln \left(\frac{H^{2}}{S K}\right)+T\left(r-\frac{\sigma^{2}}{2}\right)}{\sigma \sqrt{T}} .
\end{gathered}
$$

4. Down-and-out digital call option: If $S$ does not reach the barrier $H$, the option pays 
one unit of currency at maturity $T$ if the value of assets at maturity is greater than the strike price $K$. If $S$ reaches the barrier $H$ the option expires worthless. The value of the option with a barrier that is strictly larger than the strike price is:

$$
D B^{\text {dout }}=K e^{-r T}\left[N\left(d_{4}\right)-\left(\frac{H}{S}\right)^{\left(\frac{2 r}{\sigma^{2}}-1\right)} N\left(d_{6}\right)\right] .
$$

The value of a down-and-out digital call with a barrier which is strictly smaller than the strike price is:

$$
D B^{\text {dout }}=K e^{-r T}\left[N\left(d_{2}\right)-\left(\frac{H}{S}\right)^{\left(\frac{2 r}{\sigma^{2}}-1\right)} N\left(d_{8}\right)\right]
$$

5. Down-and-in digital call option (with payoff at touch): If $S$ reaches the barrier $H$ the option pays one unit of currency at touch. If $S$ does not reach $H$ the option expires worthless. The value of the option is:

$$
D B^{d i n}=\left(\frac{H}{S}\right)^{\frac{2 r}{\sigma^{2}}} N\left(d_{5}\right)+\frac{S}{H} N\left(d_{9}\right)
$$

where

$$
d_{9}=\frac{\ln \left(\frac{H}{S}\right)-T\left(r+\frac{\sigma^{2}}{2}\right)}{\sigma \sqrt{T}} .
$$

\section{B Choice of base case parameters}

- Maturity $(T)$ : We choose a 1-year maturity following Marcus and Shaked (1984) and Ronn and Verma (1986). A one-year maturity is reasonable given that major audits are scheduled once a year. At such a time the regulator may also ask the financial institution to change its capital structure.

- Leverage ratio $(L R)$ : The leverage ratio ranges from 0.91 to 0.95 . This range is typical for commercial and investment banks (John, Mehran, and Qian, 2010). We set the face value of the financial institution's debt to 100 and we calculate for each level of the 
leverage ratio the appropriate level of the firm's asset value, $V$.

- Asset risk $(\sigma)$ : Asset risk is set equal to $5.0 \%$, similar to the average asset risk of banks found in a large sample studied by Mehran and Rosenberg (2008). We consider a range of asset risk levels varying within two standard deviations of the mean.

- Interest rate $(r)$ : We choose a continuous constant rate of $2.5 \%$. This is on par with average annual returns on 3-month Treasury bills between 2000 and 2007.

- Contingent capital principal $\left(F^{C}\right)$ : We set the face value equal to $3 \%$ of the deposit face value, similar to the ratio in the case of Lloyds' contingent capital.

- Conversion ratio $(\alpha)$ : We set this equal to 0.5 .

- Conversion threshold $(\beta)$ : The conversion threshold is located $1 \%$ above the total face value of debt.

- Regulatory seizing policy $(\gamma)$ : We assume that the regulator seizes the bank the first time that the value of assets is $3 \%$ below the face value of the deposits. Prescott (2011) discusses losses to the deposit insurance fund during the crisis. 


\section{References}

Acharya, V., T. Cooley, M. Richardson, and I. Walter, 2009, "Real Time Solutions for Financial Reform," NYU Stern Working Group on Financial Reform.

Admati, A. R., P. M. DeMarzo, M. F. Hellwig, and P. Pfleiderer, 2010, "Fallacies, irrelevant facts, and myths in the discussion of capital regulation: Why bank equity is not expensive?," Working paper, Stanford University.

Albul, B., D. M. Jaffee, and A. Tchistyi, 2010, "Contingent Convertible Bonds and Capital Structure Decisions," Working paper, Haas School of Business, UC Berkeley.

Bebchuk, L. A., and H. Spamann, 2010, "Regulating bankers' pay," Georgetown Law Journal $98,247-287$.

Bebchuk, L. A, A. Cohen, and H. Spamann, 2010, "The wages of failure: Executive compensation at Bear Stearns and Lehman Brothers 2000-2008," Yale Journal of Regulation 27, 257-282.

Berg, Tobias , and Christoph Kaserer, 2012, "Does contingent capital induce excessive risktaking and prevent an efficient recapitalization of banks?" Working paper, HU Berlin and TU Munich.

Binder, A., 2010, "It's Broke, Let's Fix It: Rethinking Financial Regulation," International Journal of Central Banking, 6, 277-330.

Black, F., and J. Cox, 1976, "Valuing corporate securities: some effects of bond indenture provisions," Journal of Finance 31, 351-367.

Black, F., and M. Scholes, 1973, "The pricing of options and corporate liabilities," Journal of Political Economy 81, 637-654.

Bond, Philip, Itay Goldstein, and Edward Simpson Prescott, 2010, "Market-Based Corrective Actions," Review of Financial Studies 23, 781-820.

Brennan, M. J., and E. S. Schwartz, 1978, "Corporate income taxes, valuation and the problem of optimal capital structure," Journal of Business 51, 103-114.

Broadie,M., P. Glasserman, and S. Kou, 1997, "A continuity correction for discrete barrier options," Mathematical Finance 7, 325-349.

Caballero, R. J., and P. Kurlat, 2009, "The 'Surprising' Origin and Nature of Financial Crises: A Macroeconomic Policy Proposal," Working paper, Federal Banks of Kansas.

Cetin, U., R. Jarrow, P. Protter, and Y. Yildirim, 2004, "Modeling credit risk with partial Information," Annals of Applied Probability 14, 1167-1178.

Chen, Nan, Paul Glasserman, and Behzad Nouri, 2012, "CoCos, Bail-In, and Tail Risk," Working paper, Chinese University of Hong Kong and Columbia University. 
Cheng, I., H. Hong, and J. Scheinkman, 2010, "Yesterday's heros: compensation and creative risk-taking," NBER Working paper 16176.

DeYoung R., E. Y. Peng, and M. Yan., 2010, "Executive compensation and policy choices at US commercial banks," Federal Bank of Kansas, Working paper.

Duffie, D., 2009, "A Contractual Approach to Restructuring Financial Institutions," in K. B. Scott, G. P. Shultz, and J. B. Taylor eds., Ending Government Bailouts as We Know Them. Hoover Press.

Duffie, D., and D. Lando, 2001, "Term structures of credit spreads with incomplete accounting information," Econometrica 69, 633-664.

Ericsson, J., and J. Reneby, 1998, "A framework for valuing corporate securities," Applied Mathematical Finance 5, 43-163.

Flannery, M., 2002, "No Pain, No Gain? Effecting Market Discipline via Reverse Convertible Debentures," Working paper.

Flannery, M., 2009, "Stabilizing large financial institutions with contingent capital certificates," Working paper, University of Florida.

French, Kenneth R., Martin N. Baily, John Y. Campbell, John H. Cochrane, Douglas W. Diamond, Darrell Duffie, Anil K. Kashyap, Frederic S. Mishkin, Raghuram G. Rajan, David S. Scharfstein, Robert J. Shiller, Hyun Song Shin, Matthew J. Slaughter, Jeremy C. Stein, and René M. Stulz, 2010, The Squam Lake Report: Fixing the Financial System, Princeton University Press, Princeton, NJ.

Galai, D., and R. Masulis, 1976, "The option pricing model and the risk factor of stock," Journal of Financial Economics 3, 631-44.

Glasserman, P., and B. Nouri, 2011, "Contingent Capital with a Capital-Ratio Trigger," Management Science, forthcoming.

Hart, Oliver, and Luigi Zingales, 2011, "A New Capital Regulation for Large Financial Institutions," American Law and Economics Review 13, 453-490.

Jensen, M. C., and W. H. Meckling, 1976, "Rights and Production Functions: An Application to Labor-Managed Firms and Codetermination," Journal of Business 52, 469-506.

John, K., H. Mehran, and Y. Qian, 2010, "Outside Monitoring and CEO Compensation in the Banking Industry," Journal of Corporate Finance, 16, 383-399.

John, K., A. Saunders, and L. W. Senbet, 2000. "A theory of banking regulation and management compensation," Review of Financial Studies 13, 95-125.

Kashyap, A., R. Rajan, and J. Stein, 2008, "Rethinking Capital Regulation," Kansas City Symposium on Financial Stability. 
Leland, H. E., 1994, "Corporate debt value, bond covenants, and optimal capital structure," Journal of Finance, 49, 1213-1252.

Longstaff, F. A., and E. S. Schwartz, 1995, "Simple approach to valuing risky fixed and floating rate debt," Journal of Finance, 50, 789-821.

Maddaloni, A., and J. Peydró, 2009, "Bank risk-taking, securitization, supervision, and low interest rates: Evidence from lending standards," Working Paper, European Central Bank.

Marcus, A., and I. Shaked, 1984, "The valuation of FDIC deposit insurance using option pricing estimates," Journal of Money, Credit and Banking 16, 446-460.

Mehran, H., and J. Rosenberg, 2008. The Effect of CEO Stock Options on Bank Investment Choice, Borrowing, and Capital. Working paper, Federal Reserve Bank of New York.

Merton, R. C., 1973, "The theory of rational option pricing," Bell Journal of Economics and Management Science, Vol. 4, No. 1.

Merton, R. C., 1974, "On the pricing of corporate debt: the risk structure of interest rates," Journal of Finance 29, 449-70.

Pennacchi, G., 2010, "A Structural Model of Contingent Bank Capital," Working paper, University of Illinois at Urbana-Champaign.

Pennacchi, G., T. Vermaelen, and C. Wolff, 2010, "Contingent Capital: The Case for COERCs," Working paper, University of Illinois at Urbana-Champaign.

Prescott, Edward Simpson, 2011, "Contingent Capital: The Trigger Problem," Federal Reserve Bank of Richmond Working Paper 11-07.

Ronn, E. I., and A.K. Verma, 1986, "Pricing Risk-Adjusted Deposit Insurance: An Option Based Model," Journal of Finance 41, 871-896.

Rubinstein, M., and E. Reiner, 1991, "Unscrambling the Binary Code," Risk, 4.

Saunders, A., F. Strock, and N. Travlos, 1990, "Ownership structure, deregulation and bank risk-taking," Journal of Finance 45, 643-654.

Sundaresan, S., and Z. Wang, 2011, "Design of Contingent Capital with a Stock Price Trigger for Mandatory Conversion," Working paper, Federal Reserve Bank of New York. 
Table 1: Payoffs for capital structure with contingent capital

\begin{tabular}{|c|c|c|c|c|}
\hline \multirow{3}{*}{$\begin{array}{c}\text { Liability } \\
\text { Type }\end{array}$} & \multicolumn{4}{|c|}{ Scenario } \\
\hline & \multirow{2}{*}{$\begin{array}{c}\quad \tau_{C}>T \\
\\
\\
\text { (1) No early } \\
\text { conversion }\end{array}$} & \multicolumn{2}{|c|}{$\begin{array}{c}\qquad \tau_{D} \geq T \geq \tau_{C} \\
\text { (2) Early conversion }\end{array}$} & \multirow{2}{*}{$\begin{array}{c}T>\tau_{D} \\
\text { (3) Early } \\
\text { default }\end{array}$} \\
\hline & & $V_{T} \geq F^{D}$ & $V_{T}<F^{D}$ & \\
\hline Secured debt & $F^{D}$ & $F^{D}$ & $V_{T}$ & $F^{D}(1-\gamma)$ \\
\hline Coco & $F^{C}$ & $\alpha\left(V_{T}-F^{D}\right)$ & 0 & 0 \\
\hline Equity & $V_{T}-\left(F^{C}+F^{D}\right)$ & $(1-\alpha)\left(V_{T}-F^{D}\right)$ & 0 & 0 \\
\hline
\end{tabular}


Table 2: Payoffs for capital structure with subordinated debt

\begin{tabular}{|c|c|c|c|c|}
\hline & \multicolumn{3}{|c|}{ Scenario } & \multirow{2}{*}{$T \geq \tau_{D}$} \\
\hline \multirow{2}{*}{ Liability type } & \multicolumn{3}{|c|}{$(1)$ No early default } \\
\cline { 2 - 5 } & $V_{T} \geq\left(F^{D}+F^{S}\right)$ & $\left(F^{D}+F^{S}\right)>V_{T} \geq F^{D}$ & $F^{D}>V_{T}$ & \\
\hline Secured debt & $(1$. A) No default & $\begin{array}{l}(1 . \text { B }) \text { Default only on } \\
\text { subordinated debt }\end{array}$ & (1.C) Default & (2) Early default \\
\hline Subordinated debt & $F^{D}$ & $F^{S}$ & $F_{T}-F^{D}$ & $F^{D}(1-\gamma)$ \\
\hline Equity & $V_{T}-\left(F^{D}+F^{S}\right)$ & 0 & 0 & 0 \\
\hline
\end{tabular}




\section{Table 3: Parameter definitions and calibration base values}

This table reports parameter definitions and base case values. We discuss choice of parameters in more detail in the appendix.

\begin{tabular}{|c|c|c|}
\hline Description & Notation & Value \\
\hline \multicolumn{3}{|l|}{ Market Parameters } \\
\hline Bank’s assets & $\mathrm{V}$ & 108.02 \\
\hline Leverage ratio & $L R=\left(F^{D}+F^{S}\right) e^{-r T} / V$ & 0.93 \\
\hline Assets' volatility & $\sigma$ & $5 \%$ \\
\hline Risk free rate & r & $2.5 \%$ \\
\hline \multicolumn{3}{|l|}{ Claims Parameters } \\
\hline Deposit’s principal amount & $\mathrm{F}^{\mathrm{D}}$ & 100 \\
\hline Deposit and debt maturities & $\mathrm{T}$ & 1 \\
\hline Coco principal amount & $\mathrm{F}^{\mathrm{C}}, \mathrm{F}^{\mathrm{S}}$ & 3 \\
\hline Conversion ratio & $\alpha$ & $50 \%$ \\
\hline Conversion threshold & $\mathrm{K}^{\mathrm{C}}$ & $\left(\mathrm{F}^{\mathrm{S}}+\mathrm{F}^{\mathrm{D}}\right)(1+\beta)$ \\
\hline $\begin{array}{l}\text { Distance between the total debt face value and the } \\
\text { conversion threshold }\end{array}$ & $\beta$ & $1 \%$ \\
\hline \multicolumn{3}{|l|}{ Regulatory Parameters } \\
\hline Default threshold & $\mathrm{K}^{\mathrm{D}}$ & $\mathrm{F}^{\mathrm{D}}(1-\gamma)$ \\
\hline Minimum possible level of asset risk & $\sigma^{\mathrm{L}}$ & $1 \%$ \\
\hline Maximum possible level of asset risk & $\sigma^{\mathrm{H}}$ & $9 \%$ \\
\hline $\begin{array}{l}\text { The distance between the secured debt face value } \\
\text { and the default threshold }\end{array}$ & $\gamma$ & $3 \%$ \\
\hline
\end{tabular}


Table 4: Default probabilities for a bank with contingent capital and for a bank with subordinated debt

The table presents the risk neutral default probabilities in percentage for a bank with capital which is composed of coco, deposits and stock and for a bank with subordinated debt, deposits and stocks. Except for the conversion option of coco the two banks are all else identical. The levels of the parameters chosen are equal to those reported in Table 3.

\begin{tabular}{|c|c|c|c|c|}
\hline \multirow{2}{*}{ Asset risk } & \multicolumn{3}{|c|}{ Leverage ratio } \\
\cline { 2 - 5 } & & $\mathbf{9 1 \%}$ & $\mathbf{9 3 \%}$ & $\mathbf{9 5 \%}$ \\
\hline \multirow{3}{*}{ Contingent } & $1 \%$ & 0.0 & 0.0 & 0.0 \\
capital & $3 \%$ & 0.0 & 0.0 & 0.4 \\
& $5 \%$ & 0.7 & 2.3 & 6.2 \\
& $7 \%$ & 4.9 & 9.6 & 17.2 \\
& $9 \%$ & 12.3 & 19.3 & 28.9 \\
\hline \multirow{3}{*}{ Subordinated } & $1 \%$ & 0.0 & 0.0 & 0.0 \\
debt & $3 \%$ & 0.1 & 0.8 & 4.5 \\
& $5 \%$ & 3.1 & 7.7 & 16.0 \\
& $7 \%$ & 9.7 & 16.5 & 26.0 \\
& $9 \%$ & 17.4 & 25.3 & 35.2 \\
\hline \multirow{3}{*}{ The different } & $1 \%$ & 0.0 & 0.0 & 0.0 \\
between the & $3 \%$ & 0.1 & 0.8 & 4.1 \\
probabilities & $5 \%$ & 2.4 & 5.4 & 9.8 \\
& $7 \%$ & 4.8 & 6.9 & 8.8 \\
& $9 \%$ & 5.1 & 6.0 & 6.3 \\
\hline
\end{tabular}


Table 5: Optimal level of asset risk for different features of contingent capital $(\alpha, \beta)$

The table shows the level of asset risk that a stockholder trying to maximize wealth would choose for different levels of conversion ratio $(\alpha)$ and distance between the total debt face value and the conversion threshold ( $\beta$ ). We assume that the stockholder can choose asset risk that range from 1\% to $9 \%$. At each case, there are three possible results: (1) Max -The executive chooses the maximum possible level of asset risk (2) Min -The executive chooses the minimum possible level of asset risk (3) Indifference- since the difference between the maximum value of the stock and the minimum value of the stock within the range is below $0.5 \%$ of asset value, the executive is indifferent to the level of asset risk. All other data are the same as in Table 1.

\begin{tabular}{|c|c|c|c|c|c|}
\hline \multirow{2}{*}{$\begin{array}{c}\text { Conversion } \\
\text { Ratio }(\alpha)\end{array}$} & \multicolumn{5}{|c|}{ distance between the conversion threshold ( $\beta$ ) and the total debt face } \\
\cline { 2 - 6 } & $\mathbf{0 . 0} \%$ & $\mathbf{0 . 5 0 \%}$ & $\mathbf{1 . 0 0 \%}$ & $\mathbf{1 . 5 0 \%}$ & $\mathbf{2 . 0 0 \%}$ \\
\hline $\mathbf{0 \%}$ & Max & Max & Max & Max & Max \\
\hline $\mathbf{1 0 \%}$ & Max & Max & Max & Max & Max \\
\hline $\mathbf{2 0 \%}$ & Max & Max & Max & Max & Max \\
\hline $\mathbf{3 0 \%}$ & Max & Max & Max & Max & Indifferent \\
\hline $\mathbf{4 0 \%}$ & Max & Max & Max & Indifferent & Indifferent \\
\hline $\mathbf{5 0 \%}$ & Indifferent & Indifferent & Indifferent & Indifferent & Min \\
\hline $\mathbf{6 0} \%$ & Indifferent & Indifferent & Indifferent & Indifferent & Min \\
\hline $\mathbf{7 0 \%}$ & Indifferent & Min & Min & Min & Min \\
\hline $\mathbf{8 0 \%}$ & Min & Min & Min & Min & Min \\
\hline $\mathbf{9 0 \%}$ & Min & Min & Min & Min & Min \\
\hline $\mathbf{1 0 0 \%}$ & Min & Min & Min & Min & Min \\
\hline
\end{tabular}




\section{Figure 1: Time line of the model for contingent capital}

There are three possible states in the model:

(1.A) No conversion event: The value of the bank's assets does not touch the conversion threshold until debt maturity $\left(\tau_{c}>T\right)$ and the coco holder is fully paid, while the stockholder receives the residual assets.

(1.B) Conversion event with no default: The value of the bank's assets has reached the lower conversion threshold and as a result the coco holder receives a predetermined ratio of the bank's stocks in exchange for unwinding its debt obligation $\left(\tau_{d}>T \geq \tau_{c}\right)$. At maturity, if the value of the bank's assets is above the face value of debt the Coco holders and the original shareholders share the residual assets after payments are made to the secure debt holders (Path A). Otherwise, default occurs and the coco holder and the original stockholder receive nothing (Path B).

(1.C) Early default: The value of the bank's assets has touched the default threshold before maturity. $\left(\tau_{d} \leq T\right)$. The coco holder and the initial stockholders receive nothing.

\section{(1.A) No conversion}

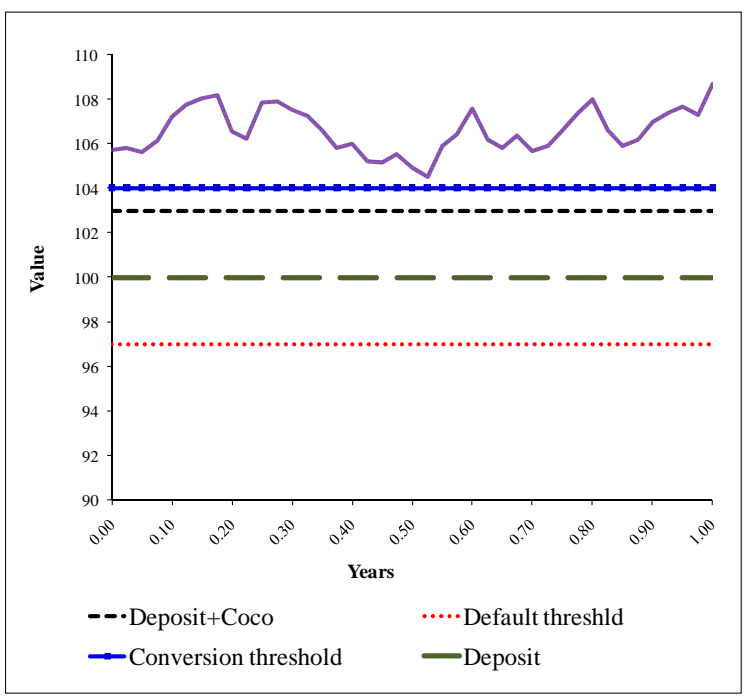

(1.B) Early conversion and no early default

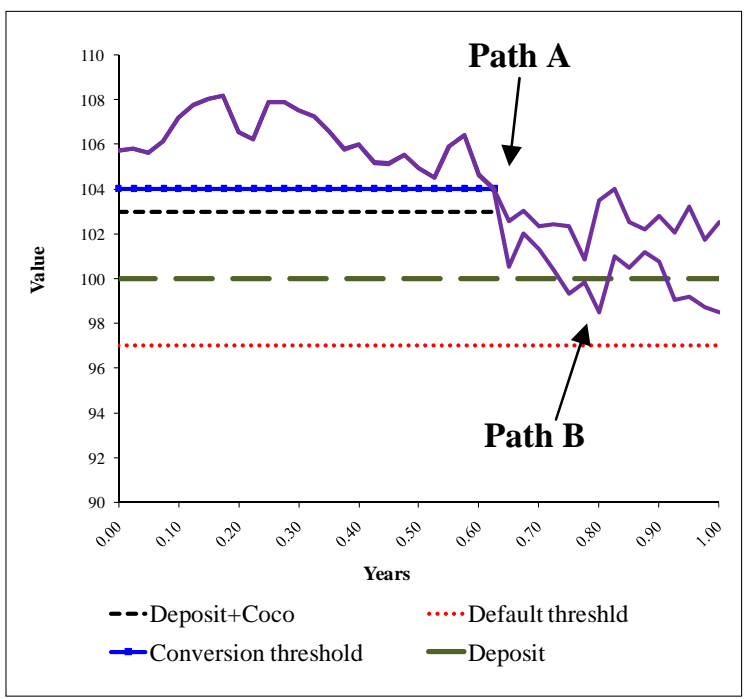

\section{(1.C) The case of early default}

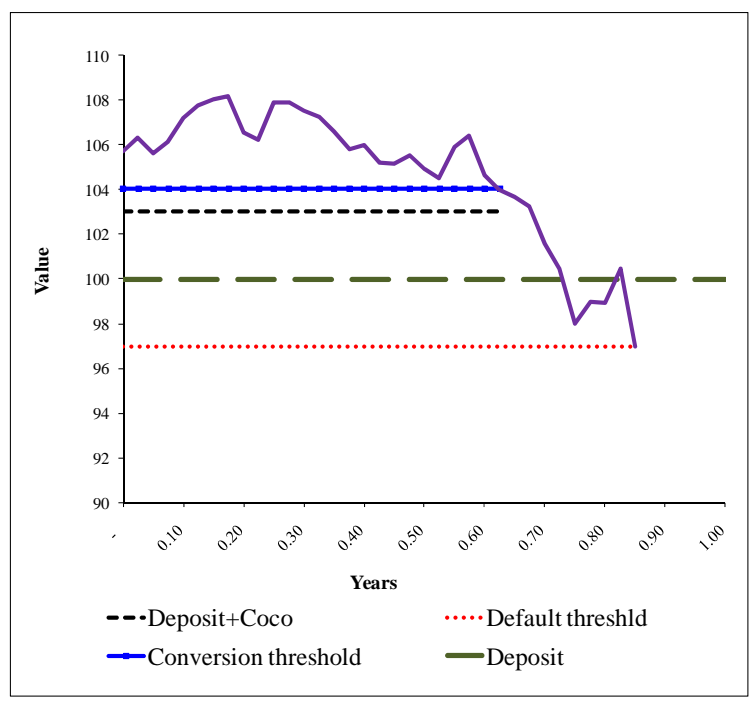




\section{Figure 2: Time line of the model for the subordinated debt}

There are two possible states in the model:

(2.A) No default: The value of the bank's assets does not touch the default threshold until debt maturity $\left(\tau_{d}>T\right)$ and the value of assets is above the total face value of debt. The subordinated debt holder is fully paid and the stockholder receives the residual assets

(2.A) Default at maturity: The value of the bank's assets does not touch the default threshold until debt maturity $\left(\tau_{d}>T\right)$, but there is default at maturity. If the value of asset is between the deposit face value and the total value of debt obligation, the subordinated debt holder receives the residual assets after the deposit holder is paid in full and the stockholder receives nothing (Path A). If the value of assets is below the face value of debt and both the subordinated debt holder and the stockholder receive nothing (Path B).

(2.C) Early default: The value of the bank's assets touches the default threshold before maturity $\left(\tau_{d} \leq T\right)$. The subordinated debt holder and the stockholder receive nothing.

\section{(2.A) No default}

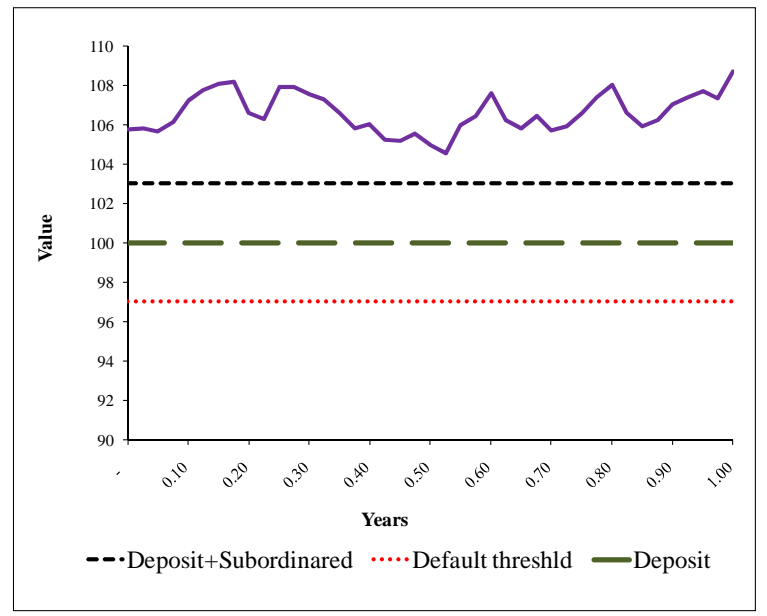

(2.B) Default at Maturity

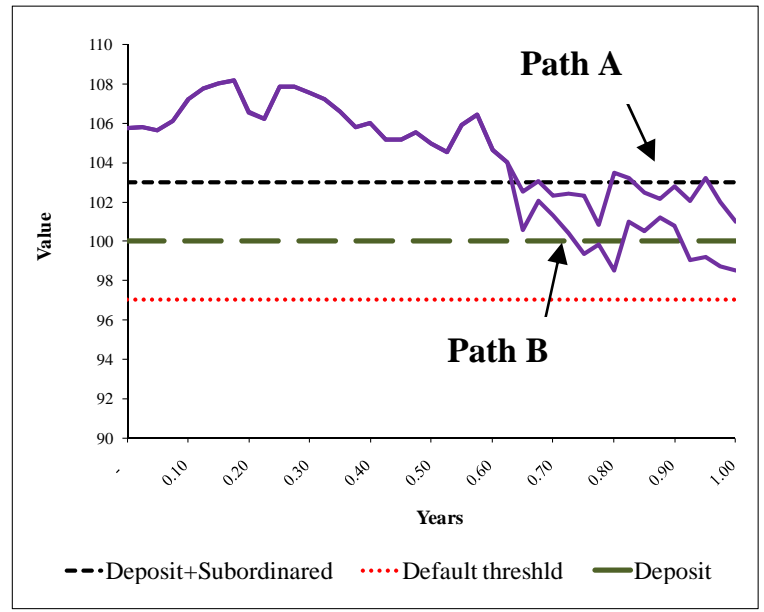

\section{(2.C) The case of early default}

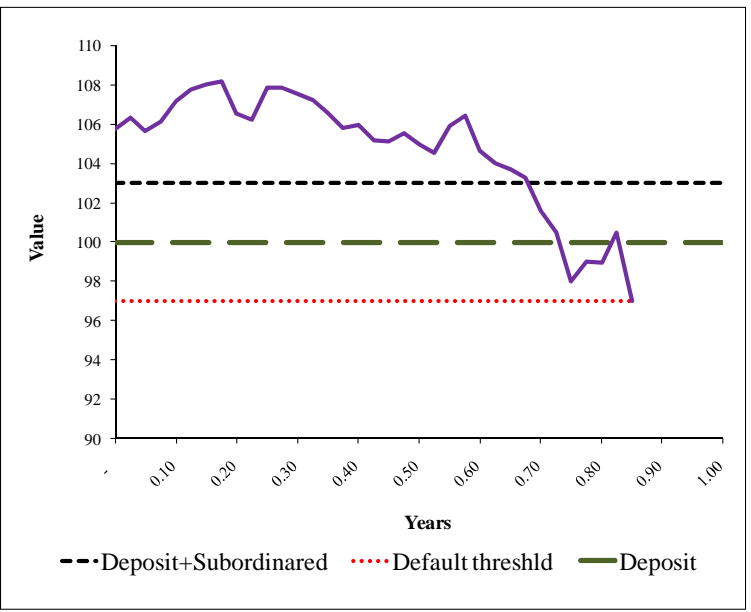




\section{Figure 3: Stock value versus asset risk for different conversion ratios}

The figure presents the value of stock versus asset risk for different conversion ratios $(\alpha)$ where the bank capital structure is composed of coco, deposits and stocks. All other parameters are identical to the base case parameters (see Table 3).

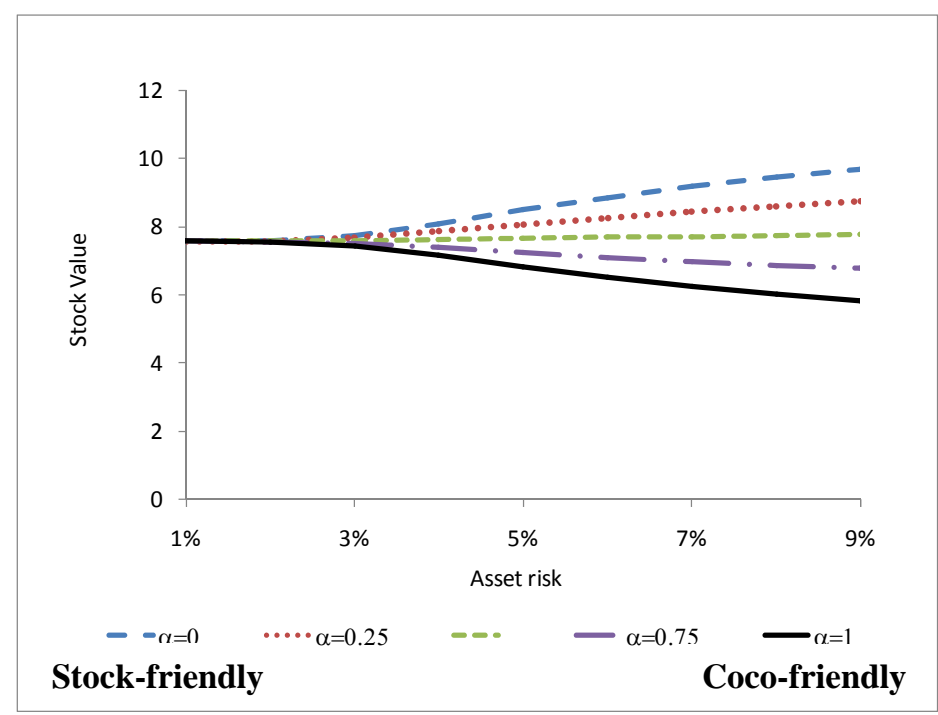




\section{Figure 4: Stock value versus asset risk for different conversion thresholds}

The figure presents the value of a stock of a financial institution with Coco as part of its capital structure versus assets risk for different distance between the conversion threshold and the firm's book value of debt $(\beta)$. The conversion ratio $(\alpha)$ is equal at panel (4.A) to 0.9 , and to 0.5 and 0.1 at panels (4.B) and (4.C) respectively. All other parameters are identical to the base case parameters (see Table 3).

\section{(4.A) "Stock friendly"}

Low conversion ratio $(\alpha=0.1)$

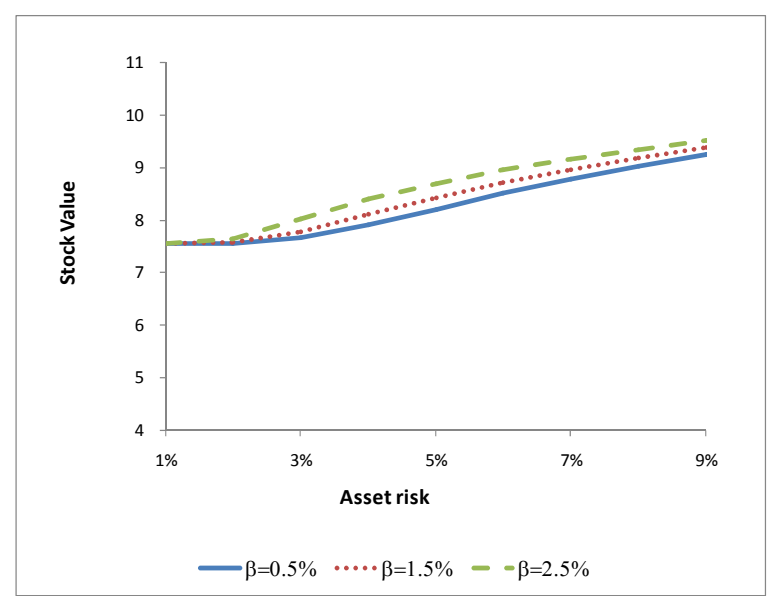

\section{(4.B) Moderate conversion ratio}

The conversion ratio $(\alpha)$ is equal to 0.5

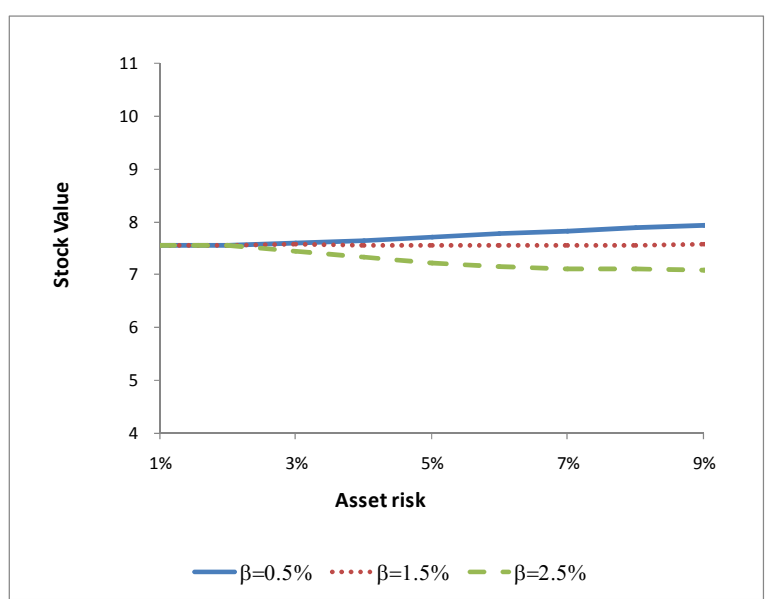

\section{(4.C) “Coco friendly"}

High conversion ratio $(\alpha=0.9)$

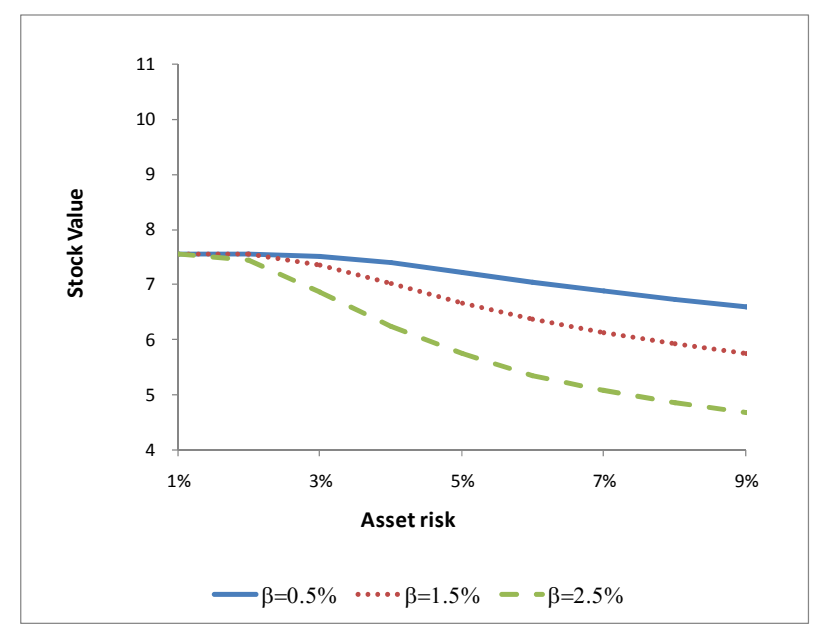




\section{Figure 5: Stock value for versus asset risk for different leverage ratios}

The figure presents the value of a stock versus asset risk in a bank with a capital structure which includes coco, deposits and stocks. The conversion ratio $(\alpha)$ is equal in panel (5.A) to $10 \%$ ("Stock Friendly") and to 90\% ("Coco friendly") in panel (5.B). In each case the leverage ratio receives values of 0.91, 0.93 and 0.95 . All other parameters are identical to the base case parameters (See Table 3).

\section{(5.A) “Stock friendly”}

Low conversion ratio $(\alpha=0.1)$

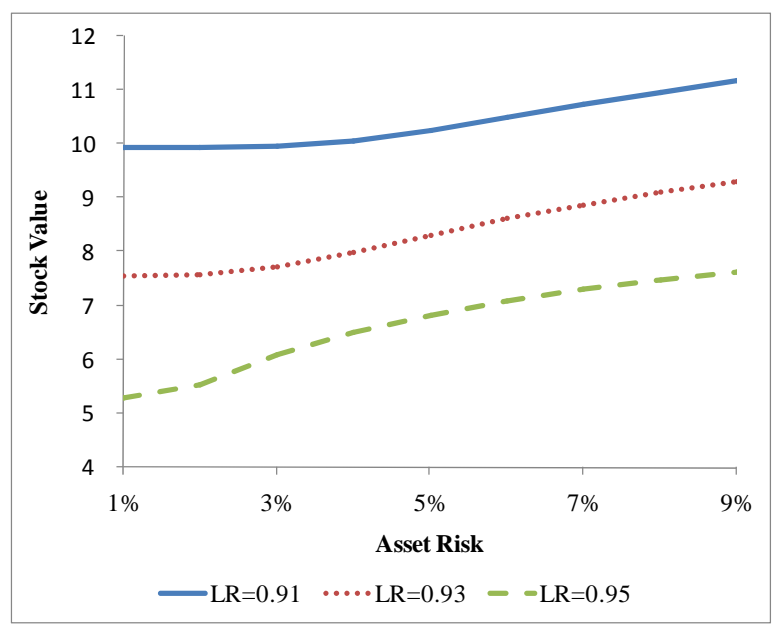

\section{(5.B) "Moderate conversion ratio"}

Conversion ratio is equal $\alpha=0.5$

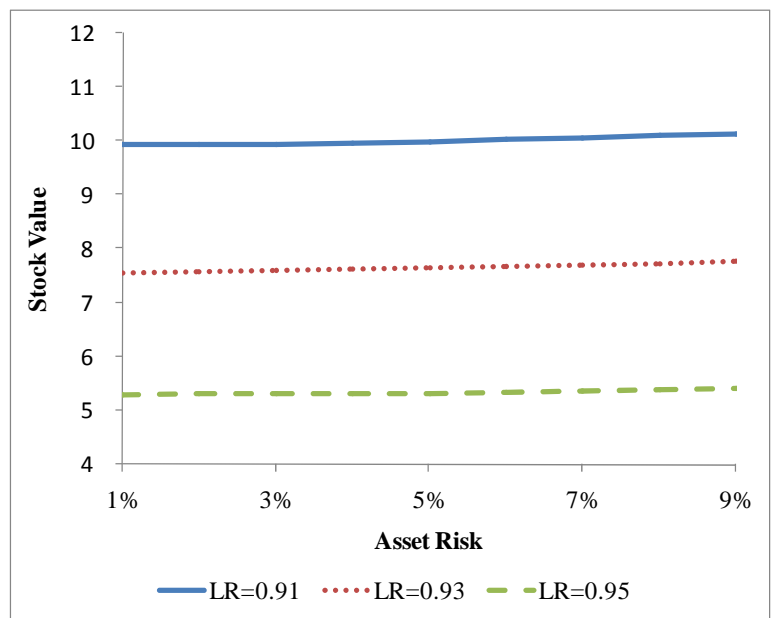

\section{(5.C) “Coco friendly”}

High conversion ratio $(\alpha=0.9)$

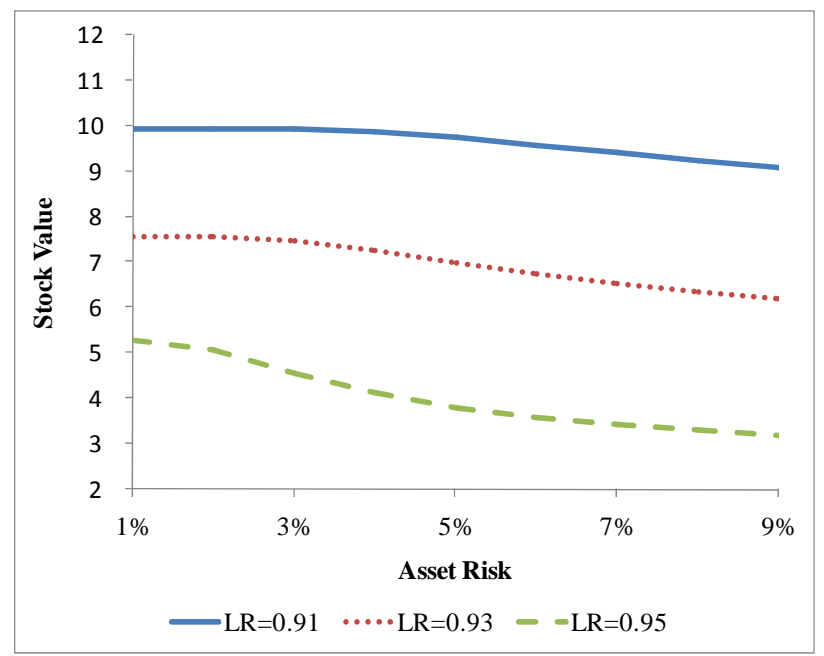




\section{Figure 6: Stock value versus asset risk for different regulatory policies}

The figure presents the value of a stock versus asset risk in a bank with a capital structure which includes deposits, coco and stocks for different regulatory seizing policies. The ability and will of the regulator determine the level of the threshold in which the bank is seized by the regulator. This level is expressed by the parameter $\gamma$, which is the percentage negative difference between the face value of the deposits and the seizing threshold. All other parameters (conversion ratio, conversion threshold etc.) are identical to the base case parameters (see Table 3).

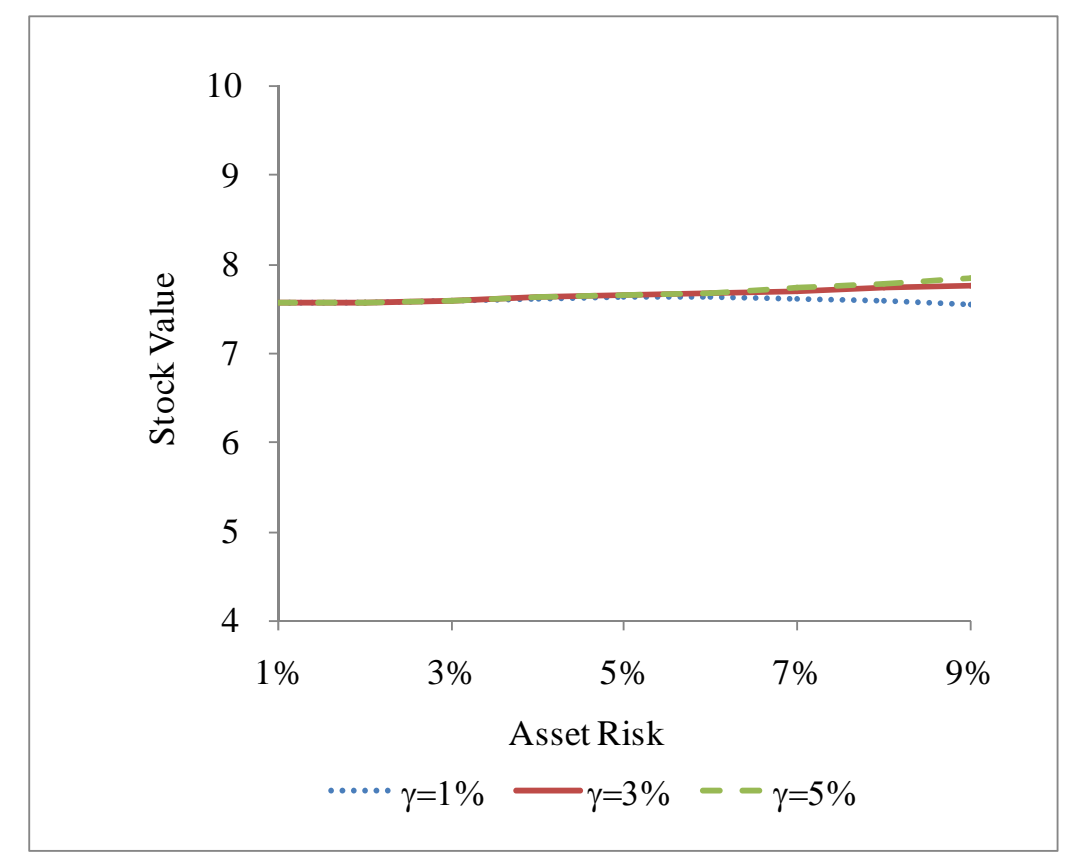




\section{Figure 7: Stock value versus asset risk for different capital structures}

Figure (7.A) presents the value of a stock versus asset risk for a bank with a capital structure which includes coco, deposits and stocks. Figure (7.B) presents the value of a stock versus asset risk for a bank with only deposits and stocks. In each case the leverage ratio receives values of $0.91,0.93$ and 0.95 . All other parameters are identical to the base case parameters (See Table 3).

(7.A) Capital structure with subordinated debt

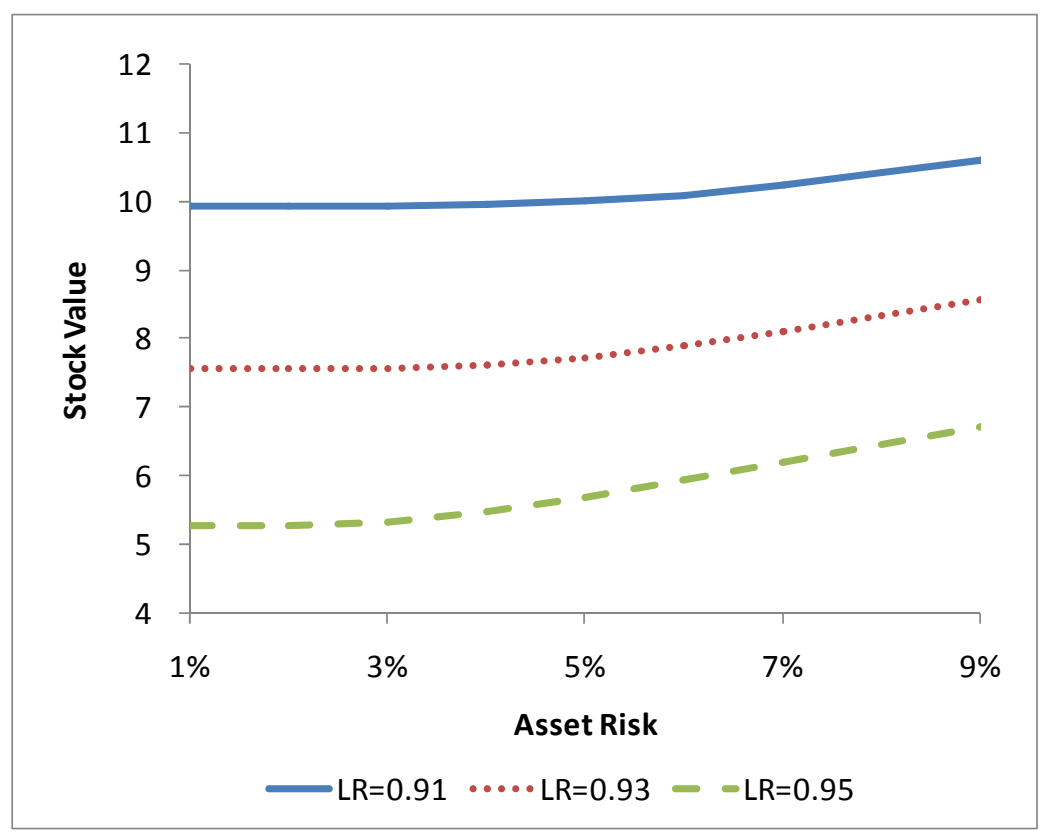

(7.B) Capital structure with stock only

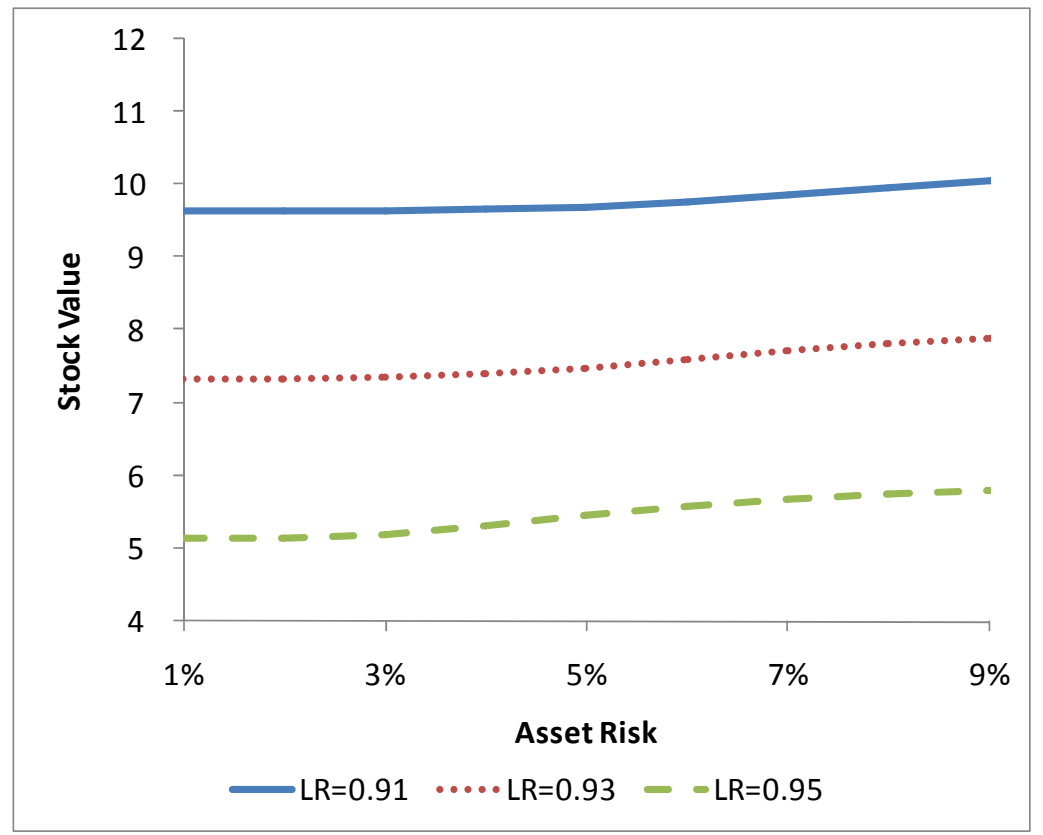




\section{Figure 8: Stock value versus asset risk for different monitoring frequency}

Figure (8.A) presents the value of a stock versus asset risk for different monitoring frequency in which information is received about the value of the firm assets and the conversion covenant may be executed. In panel (8.A), as in the base case, the distance between the total face value of debt and the conversion ratio is equal to $1 \%$ while in panel (8.B) the ratio is increased to $3 \%$ (the parameter $\beta$ ). All other parameters are identical to the base case parameters (see Table 3).

(8.A) Conversion threshold which is located $1 \%$ above the total face value of $\operatorname{debt}(\beta=1 \%)$

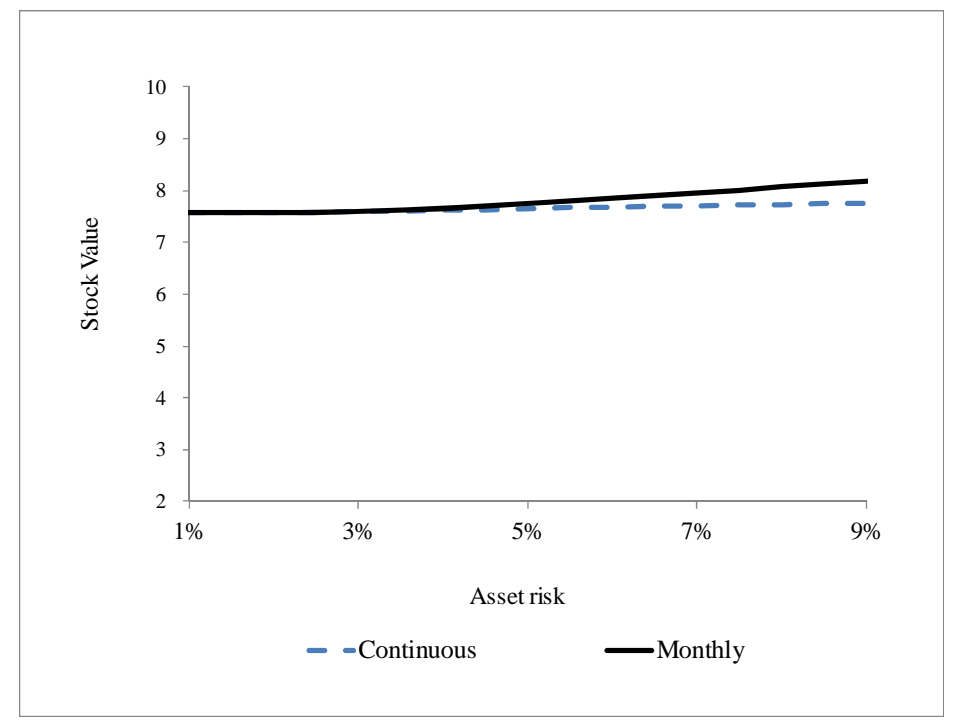

(8.B) Conversion threshold which is located $3 \%$ above the total face value of debt $(\beta=3 \%)$

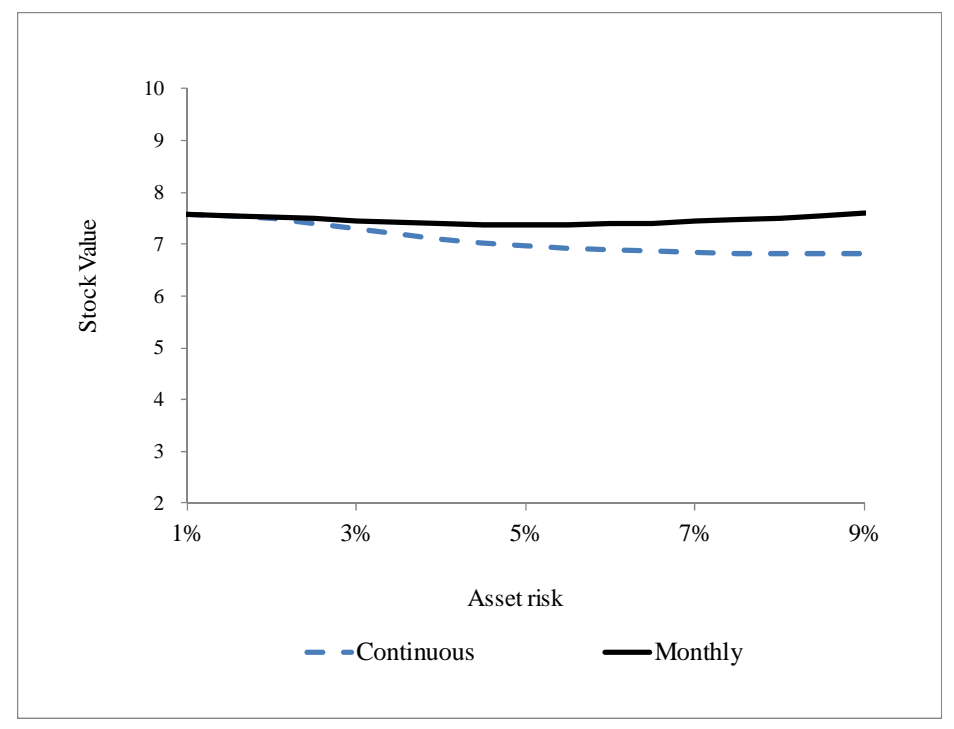




\section{Figure 9: Coco value versus asset risk for different conversion ratios}

The figure presents the value of coco versus asset risk for a financial institution with a capital structure that is composed of coco, deposits, and stock. We vary the level of the conversion ratio $(\alpha)$. All other parameters are identical to the base case parameters (see Table 3).

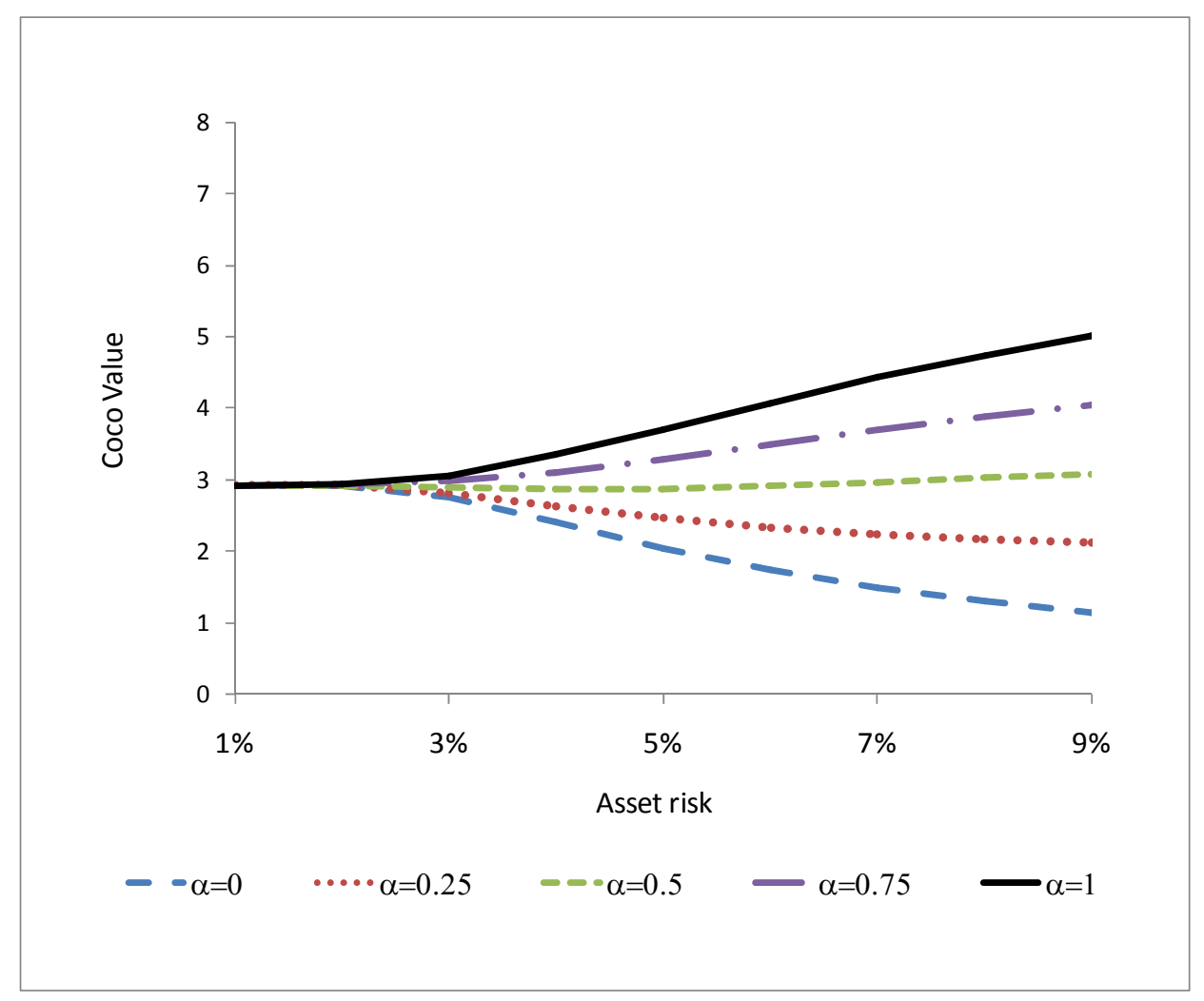

